ARTICLE

DOI: $10.1038 / s 41467-017-00468-w$

\title{
Selective degradation of PU.1 during autophagy represses the differentiation and antitumour activity of $\mathrm{T}_{\mathrm{H}} 9$ cells
}

Thaiz Rivera Vargas ${ }^{1,2}$, Zhijian Cai ${ }^{3}$, Yingying Shen ${ }^{3}$, Magalie Dosset1,2,4, Isis Benoit-Lizon ${ }^{1,2}$, Tiffany Martin ${ }^{1,2}$, Aurélie Roussey ${ }^{1,2}$, Richard A. Flavell ${ }^{5,6}$, François Ghiringhelli, ${ }^{1,7}$ \& Lionel Apetoh (10) 1,2,7

Autophagy, a catabolic mechanism that involves degradation of cellular components, is essential for cell homeostasis. Although autophagy favours the lineage stability of regulatory $T$ cells, the contribution of autophagy to the differentiation of effector CD4 T cells remains unclear. Here we show that autophagy selectively represses $T$ helper $9\left(T_{H} 9\right)$ cell differentiation. CD4 T cells lacking Atg3 or Atg5 have increased interleukin-9 (IL-9) expression upon differentiation into $\mathrm{T}_{\mathrm{H}} 9$ cells relative to Atg3- or Atg5-expressing control cells. In addition, the $\mathrm{T}_{\mathrm{H}} 9$ cell transcription factor, PU.1, undergoes $\mathrm{K} 63$ ubiquitination and degradation through p62-dependent selective autophagy. Finally, the blockade of autophagy enhances $T_{H} 9$ cell anticancer functions in vivo, and mice with $T$ cell-specific deletion of Atg 5 have reduced tumour outgrowth in an IL-9-dependent manner. Overall, our findings reveal an unexpected function of autophagy in the modulation of $\mathrm{T}_{\mathrm{H}} 9$ cell differentiation and antitumour activity, and prompt potential autophagy-dependent modulations of $T_{H} 9$ activity for cancer immunotherapy.

\footnotetext{
${ }^{1}$ INSERM, U1231, Dijon 21000, France. ${ }^{2}$ Université de Bourgogne Franche Comté, Dijon 21000, France. ${ }^{3}$ Institute of Immunology, Zhejiang University Schoo of Medicine, Hangzhou, People's Republic of China. ${ }^{4}$ Etablissement Français du Sang, Besançon 25000, France. ${ }^{5}$ Department of Immunobiology, Yale University School of Medicine, New Haven, Connecticut 06520, USA. ${ }^{6}$ Howard Hughes Medical Institute, Yale University School of Medicine, New Haven, Connecticut 06520, USA. ${ }^{7}$ Centre Georges François Leclerc, Dijon 21000, France. Thaiz Rivera Vargas and Zhijian Cai contributed equally to this work. François Ghiringhelli and Lionel Apetoh jointly supervised this work. Correspondence and requests for materials should be addressed to

F.G. (email: fghiringhelli@cgfl.fr) or to L.A. (email: lionel.apetoh@inserm.fr)
} 
M acroautophagy (henceforth referred to as autophagy) is a highly conserved catabolic mechanism responsible for organelles turnover, membrane recycling and protein degradation ${ }^{1,2}$. This dynamic process involves the formation of double-membrane vesicles termed autophagosomes, which engulf portions of the cytoplasm and then fuse with lysosomes for degradation. Under cell stress, autophagy can serve as a survival mechanism allowing the reuse of cytosolic constituents ${ }^{3}$. Autophagy is initiated through a well-conserved molecular pathway that involves the Atg5-Atg12 covalent protein complex and microtubule-associated protein 1 light chain 3 (LC3, homologous to yeast Atg8) ${ }^{4}$. Subsequently, Atg16L1 promotes the conjugation of LC3 to phosphatidylethanolamine, resulting in autophagosome formation ${ }^{5}$.

Autophagy can also selectively target specific long-lived proteins, protein complexes, protein aggregates, various organelles and even intracellular microbes for destruction. This process, referred to as selective autophagy, can drive the degradation of specific proteins through recognition of ubiquitinated cargos via ubiquitin-binding domains of adaptor proteins ${ }^{6}$. Selective autophagy employs dedicated cargo adaptors such as $\mathrm{p} 62$, an adaptor protein that specifically targets, recruits and degrades a certain type of cargo in response to various intracellular or extracellular signals ${ }^{9}$. These adaptor proteins bind simultaneously to cargo and lipidated LC3 to selectively recruit the autophagy machinery to induce autophagosome formation ${ }^{6,7}$. Selective degradation of key regulatory proteins in a timely and spatially regulated manner is essential for processes like gene expression, cell cycle progression, apoptosis and cell differentiation.

Autophagy has contrasting roles in cancer ${ }^{8,9}$. While autophagy is required for immunogenic cell death process and acts as a tumour suppression mechanism ensuring the suppression of DNA damage and genomic instability as well as promoting protein quality control, autophagy also enables tumour cell survival in the tumour microenvironment and thereby supports tumour outgrowth ${ }^{8,9}$. Accordingly, thyroid carcinoma patients carrying the autophagy-preventing single-nucleotide polymorphism (SNP) Thr300Ala of the ATG16L1 gene have improved clinical outcomes ${ }^{10}$. Likewise, the ATG16L1 Thr300Ala SNP is associated with a reduced risk of metastasis in colorectal cancer patients ${ }^{11}$.

Autophagy controls T-cell homeostasis, as illustrated by its requirement for the activation, proliferation and survival of $\mathrm{T}$ cells ${ }^{12-14}$. Autophagy also contributes to the formation of $\mathrm{CD}^{+}$memory $\mathrm{T}$ cells ${ }^{15}$, and couples environmental signals and metabolic homeostasis to protect lineage integrity and survival of regulatory $\mathrm{T}$ cells ${ }^{16}$. In line with this, autophagy induction following T-cell receptor (TCR) activation is shown to promote CD4 T-cell survival and antigen-dependent proliferation ${ }^{17}$. Autophagy is also observed in T helper $1\left(\mathrm{~T}_{\mathrm{H}} 1\right)$ and $\mathrm{T}$ helper 2 $\left(\mathrm{T}_{\mathrm{H}} 2\right)$ cells upon differentiation from naive $\mathrm{T}$ cells ${ }^{17}$. Despite these observations demonstrating the potential relevance of the autophagic process in $\mathrm{T}$ cells, the functions of autophagy in effector T-cell differentiation remains incompletely understood.

Here we investigate the function of autophagy in the differentiation of effector CD4 $\mathrm{T}$ cells. We find that autophagy selectively restrains $\mathrm{T}_{\mathrm{H}} 9$ cell polarization. $\mathrm{CD} 4 \mathrm{~T}$ cells lacking autophagy-essential genes Map1lc3b (encoding LC3 B), Atg3 or Atg5 have increased interleukin-9 (IL-9) secretion upon differentiation into $\mathrm{T}_{\mathrm{H}} 9$ cells. Under $\mathrm{T}_{\mathrm{H}}$ 9-skewing conditions, the $\mathrm{T}_{\mathrm{H}} 9$ cell transcription factor PU.1 undergoes ubiquitination and degradation through p62-dependent selective autophagy. Importantly, inhibition of autophagy in $\mathrm{T}_{\mathrm{H}} 9$ cells enhances their anticancer functions in vivo, and mice with $\mathrm{T}$ cell-specific deletion of Atg5 have reduced tumour outgrowth in an
IL-9-dependent manner. These results implicate selective autophagy in the modulation of $\mathrm{T}_{\mathrm{H}} 9$ cell differentiation and prompt a potential mechanism for enhancing $\mathrm{T}_{\mathrm{H}} 9$ cell antitumour properties.

\section{Results}

Autophagy controls IL-9 secretion from $\mathrm{T}_{\mathrm{H}} \mathbf{9}$ cells. To test the contribution of autophagy in CD4 T-cell differentiation, we selectively suppressed T-cell expression of Atg5, a protein required for autophagy, by crossing Atg5-floxed mice to CD4 Cre mice and differentiated naive Atg5-deficient CD4 T cells (Atg5fl/fl ${ }^{*} \mathrm{CD} 4$-Cre) into $\mathrm{T}_{\mathrm{H}} 1, \mathrm{~T}_{\mathrm{H}} 2, \mathrm{~T}_{\mathrm{H}} 17$ and $\mathrm{T}_{\mathrm{H}} 9$ effector subsets as well as into regulatory $\mathrm{T}$ (Treg) cells using plate-bound anti-CD3 and anti-CD28 antibody stimulation and selective choice of differentiating cytokines (Supplementary Fig. 1a, b, c). We noted that Atg5 deficiency failed to affect the secretion of the $\mathrm{T}_{\mathrm{H}} 1$ and $\mathrm{T}_{\mathrm{H}} 17$ cytokines interferon- $\gamma$ (IFN- $\gamma$ ) and IL-17 respectively and modestly induced IL-4, IL- 5 and IL- 13 from $\mathrm{T}_{\mathrm{H}} 2$ cells without reaching a significant increase by enzyme-linked immunosorbent assay (ELISA) analysis of IL-4 and IL-5 cytokines (Fig. 1 and Supplementary Fig.1d). By contrast, we found that in the absence of $\operatorname{Atg} 5, \mathrm{~T}_{\mathrm{H}} 9$ cell differentiation was markedly increased, as illustrated by a fivefold increase in IL-9 secretion from differentiating $\mathrm{T}_{\mathrm{H}} 9$ cells measured by ELISA (Fig. 1a). In line with Wei et al. ${ }^{16}$, we found that Treg cell differentiation was significantly decreased in the absence of Atg5 (Fig. 1b). These results were confirmed by real-time PCR (RT-PCR) analysis and intracellular cytokine staining (Fig. 1b, c). Similar results were also obtained using $\mathrm{CD} 4 \mathrm{~T}$ cells from Atg5-floxed mice (Atg5fl/fl) transduced with a Cre overexpressing vector (Supplementary Fig. 1e, f). Because it was previously described that Atg5 affects $\mathrm{T}$-cell proliferation and survival ${ }^{12}$, we investigated the impact of Atg5 deficiency on $\mathrm{T}_{\mathrm{H}} 9$ cell proliferation and survival. We found that $\mathrm{T}_{\mathrm{H}} 9$ cells from Atg $5^{f l / f f^{*} \mathrm{CD} 4 \text {-Cre }}$ mice expressed higher levels of Ki67 than those in WT $\mathrm{T}_{\mathrm{H}} 9$ cells, suggesting that Atg5 is dispensable for $\mathrm{T}_{\mathrm{H}} 9$ cell proliferation (Supplementary Fig. 1c, g, h). $\mathrm{T}_{\mathrm{H}} 9$ cells from Atg5-deficient mice exhibit enhanced apoptosis compared to WT cells as detected by annexin V and 7-aminoactinomycin D (7-AAD) staining (Supplementary Fig. 1b, i, j). These results are in line with the work of Chi and co-workers ${ }^{16}$ who showed that Atg7-deficient Treg cells undergo increased cell death but increased proliferation.

We have tested whether autophagy deficiency affects $\mathrm{T}$-cell survival and proliferation of $T_{H} 1, T_{H} 2, T_{H} 9, T_{H} 17$ and Treg cells in our settings. In line with previous studies ${ }^{13,16}$, we noted upon autophagy blockade an increase in cell death and proliferation of all the $\mathrm{CD} 4^{+} \mathrm{T}$-cell subsets studied following activation except for $\mathrm{T}_{\mathrm{H}} 17$ cells that proliferated like controls $72 \mathrm{~h}$ after differentiation initiation (Supplementary Fig. 1k, l, m). Importantly, although these observations did not translate into significant alterations of the overall cytokine accumulation during the course of $\mathrm{T}_{\mathrm{H}} 1, \mathrm{~T}_{\mathrm{H}} 2$ and $\mathrm{T}_{\mathrm{H}} 17$ cell differentiation, we noted a fivefold increase in IL-9 secretion from autophagy-deficient $\mathrm{T}_{\mathrm{H}} 9$ cells (Fig. 1a). Overall, this indicates that autophagy blockade favours $\mathrm{T}_{\mathrm{H}} 9$ cell differentiation rather than inhibiting the differentiation of other effector T-cell subsets.

To further test whether $\operatorname{Atg} 5$ affects $\mathrm{T}_{\mathrm{H}} 9$ cell differentiation, we knocked down Atg5 expression in wild-type (WT) CD4 T cells using small interfering RNA (siRNA). In line with our results obtained using conditional deficient mice, we found that preventing Atg5 expression in $\mathrm{T}_{\mathrm{H}} 9$ cells enhanced their secretion of IL-9 (Fig. 1d and Supplementary Fig. 1n). Moreover, Atg5 deficiency failed to enhance IL-9 expression in $\mathrm{T}_{\mathrm{H}} 1, \mathrm{~T}_{\mathrm{H}} 2, \mathrm{~T}_{\mathrm{H}} 17$ and Treg cells, suggesting that Atg5 deficiency does not skew other effector or regulatory subsets towards a $\mathrm{T}_{\mathrm{H}} 9$ differentiation 

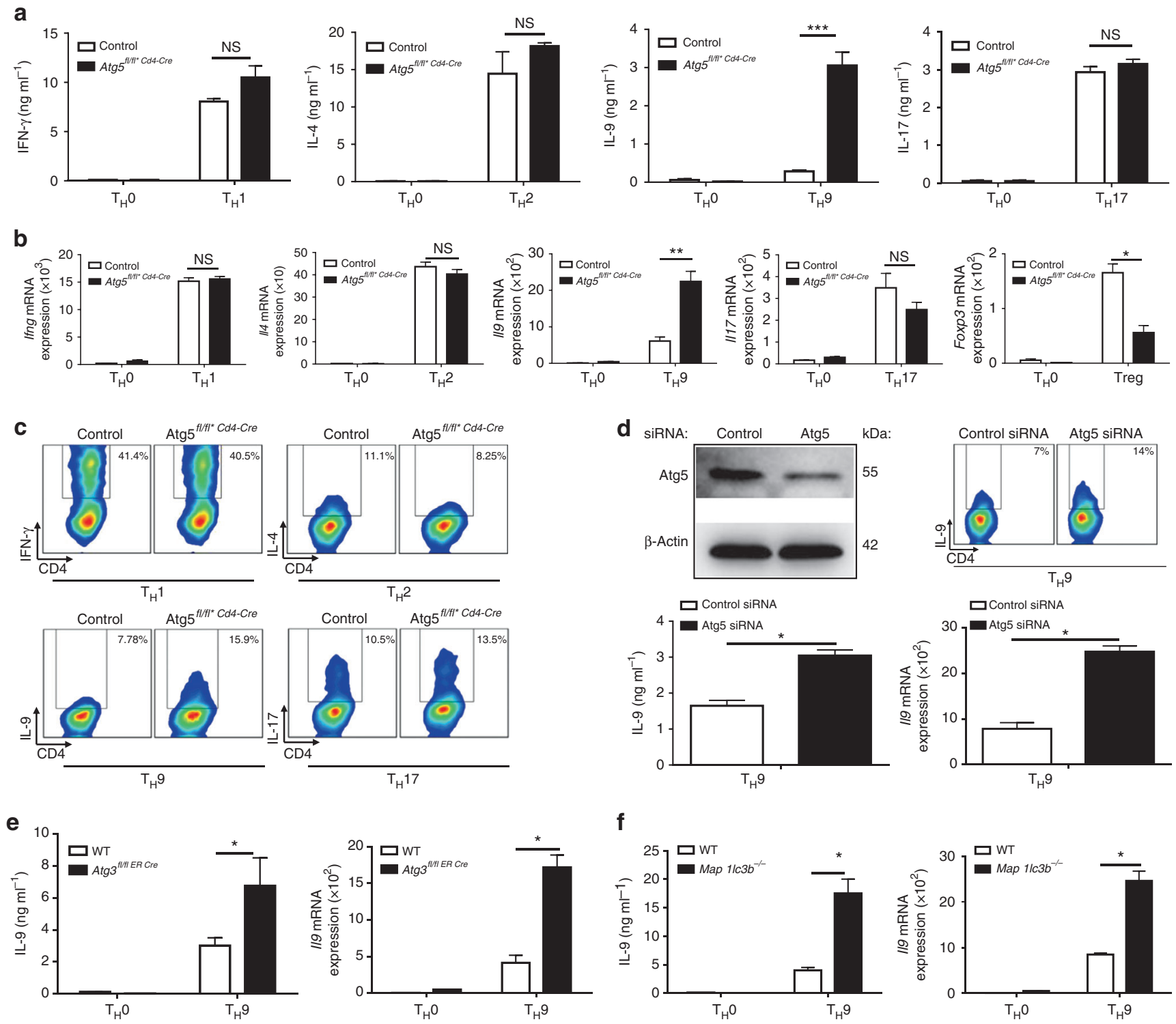

Fig. 1 The autophagy-related proteins Atg5, Atg3 and LC3-II negatively regulate $T_{H} 9$ cell differentiation in vitro. Cell-sorted naive CD4 ${ }^{+} C D 62 L^{\text {hi }} C D 44^{l o}$ $T$ cells were isolated from control and conditional Atg5-deficient (Atg $5^{f / f /\left.\right|^{*} C D 4-C r e}$ ) mice and differentiated into $T_{H} 0, T_{H} 1, T_{H} 2, T_{H} 9$ and $T_{H} 17$ cells in the presence of plate-bound anti-CD3 and anti-CD28 antibodies for $72 \mathrm{~h}$. a ELISA of IFN- $\gamma_{1}$ IL-4, IL- 9 and IL-17 in supernatants of $T_{H} 0$, $T_{H} 1, T_{H} 2, T_{H} 9$ and $T_{H} 17$ cells differentiated for 3 days from Atg $5^{f / /{ }^{*} C D 4-C r e}$ and Atg $5^{f / f / l^{*} C D 4-C r e}$ naive CD4 ${ }^{+} \mathrm{T}$ cells. b Quantitative RT-PCR analysis of Ifng, II4, II9, II17 and Foxp3

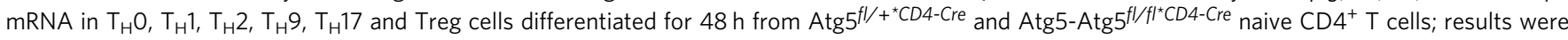
normalized to the expression of $A c t b$ (encoding $\beta$-actin) and are presented relative to control $T_{H} 0$ cells. Experiment performed three times. $\mathbf{c}$ Flow cytometry analysis of IFN- $\gamma, \mathrm{IL}-4, \mathrm{IL}-9$, and IL-17 expression from $\mathrm{T}_{\mathrm{H}} 1, \mathrm{~T}_{\mathrm{H}} 2, \mathrm{~T}_{\mathrm{H}} 9$ and $\mathrm{T}_{\mathrm{H}} 17$ cells differentiated for 3 days from Atg 5 fl/ $+{ }^{*} \mathrm{CD} 4-\mathrm{Cre}$ and Atg $5^{f / / f l^{*} C D 4-C r e}$ naive $C D 4^{+} T$ cells. $\mathbf{d} T_{H} 9$ cells transfected with control siRNA or Atg5 siRNA. Atg5 inhibition was assessed by western blot. IL-9 expression was analysed by ELISA, qRT-PCR and flow cytometry. Experiment performed twice. Mean (+s.d.), paired Student's $t$-test two-tailed. e, $\mathbf{f}$ IL-9 expression assessed by ELISA and qRT-PCR from $\mathrm{T}_{\mathrm{H}} 9$ cells differentiated for 3 days from naive WT, Atg3-deficient $\left(\operatorname{Atg} 3^{-/-}\right.$) and Map $1 / \mathrm{c} 36$-deficient

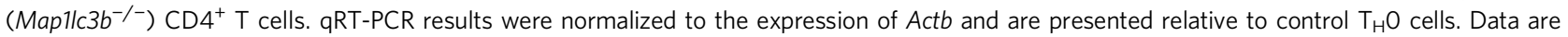
representative of three experiments. Mean (+s.d.), NS, not significant with $P>0.05$; ${ }^{\star} P<0.05$; ${ }^{\star \star} P<0.01$; ${ }^{\star \star \star} P<0.01$; two-way analysis of variance (ANOVA) test

programme (Supplementary Fig. 10). We have eventually investigated the involvement of Atg3 and LC3, both of which are required for autophagy ${ }^{18}$, in $\mathrm{T}_{\mathrm{H}} 9$ cell differentiation using Atg3- and Map1lc3b-deficient T cells. In line with our results obtained with Atg5-deficient mice, we found that CD4 T cells lacking Atg3 or Map1lc3b featured enhanced ability to differentiate into $\mathrm{T}_{\mathrm{H}} 9$ cells compared to control cells (Fig. 1e, f), thereby demonstrating that deficiency of any key autophagy gene endows CD4 cells with augmented IL-9 secretion under
$\mathrm{T}_{\mathrm{H}}$ 9-skewing conditions. Overall, these results show that the expression of Atg5 in differentiating $\mathrm{T}_{\mathrm{H}} 9$ cells cell-intrinsically and specifically represses their secretion of IL-9.

While Atg5 is a key gene in the induction of autophagy ${ }^{19}$, it has been reported that Atg 5 could also signal independently of autophagy ${ }^{20}$. Thus, to test further the putative involvement of autophagy during $\mathrm{T}_{\mathrm{H}} 9$ cell differentiation, we next assessed the induction of autophagy in differentiating $\mathrm{T}_{\mathrm{H}} 9$ cells upon in vitro differentiation. Because the most reliable indicator of autophagic 
activity is the autophagic flux defined by the whole process of autophagosome synthesis followed by delivery to and degradation within lysosomes, we have monitored the autophagic flux in differentiating $\mathrm{T}_{\mathrm{H}} 9$ cells. Since LC3-II is degraded in autophagolysosomes we monitored LC3 turnover to measure autophagic flux. For this, we have differentiated naive CD4 $\mathrm{T}$ cells into $\mathrm{T}_{\mathrm{H}} 9$ cells in the presence or not of chloroquine, which prevents lysosomal degradation ${ }^{21}, 22$, and assessed LC3-II expression representing the amount of LC3-II that is delivered to lysosomes for degradation. Our time-course experiment showed higher levels of LC3-II in differentiating $\mathrm{T}_{\mathrm{H}} 9$ cells treated with chloroquine compared to control cells at every time point, strongly suggesting that the full process of autophagy occurs in differentiating $\mathrm{T}_{\mathrm{H}} 9$ cells (Fig. 2a, b and Supplementary Fig. 2a). In addition, when comparing autophagy levels in $\mathrm{T}_{\mathrm{H}}$ cells, we found that $\mathrm{T}_{\mathrm{H}} 9$ cells featured comparable levels of lipidated LC3 (LC3-II) to $\mathrm{T}_{\mathrm{H}} 2$ and Treg cells, in which the induction of autophagy was previously shown ${ }^{16,17}$ (Fig. 2c and Supplementary Fig. 2b). In the absence of Atg5, LC3-II expression is impaired during $\mathrm{T}_{\mathrm{H}} 9$ cell differentiation (Fig. 2d and Supplementary Fig. 2c), showing that Atg5 deficiency completely blunts autophagy in $\mathrm{T}_{\mathrm{H}} 9$ cells, thus demonstrating its capital function in $\mathrm{T}_{\mathrm{H}} 9$ autophagy process. Altogether, these results indicate that the genetic prevention of autophagy enhances $\mathrm{T}_{\mathrm{H}} 9$ cell generation in vitro.

Pharmacological modulation of autophagy affects $T_{H} \mathbf{9}$ cells. Several clinically approved drugs such as metformin and chloroquine have been shown to regulate autophagy ${ }^{23-25}$. Because our results showed that differentiating $\mathrm{T}_{\mathrm{H}} 9$ cells undergo autophagy, which represses their IL-9 secretion, we hypothesized that drugs affecting autophagy would also modulate $\mathrm{T}_{\mathrm{H}} 9$ cell differentiation. To test this, we have differentiated $\mathrm{T}_{\mathrm{H}} 9$ cells in the presence or not of metformin and chloroquine, which respectively induce and block autophagy ${ }^{23-25}$. We found that metformin and chloroquine respectively prevented and enhanced $\mathrm{T}_{\mathrm{H}} 9$ cell differentiation in a dose-dependent manner (Fig. 3a, b). To track the effect of metformin and chloroquine on IL-9expressing cells in real time and at the single cell level, we used IL-9-EGFP mice ${ }^{26}$. Differentiation of naive CD4 T cells obtained from IL-9-EGFP mice into $\mathrm{T}_{\mathrm{H}} 9$ cells in the presence of metformin decreased IL- 9 secretion measured by ELISA and quantitative PCR (qPCR) (Fig. 3c) and both reduced the frequency and mean fluorescence intensity of IL-9-expressing cells 3 days following differentiation initiation (Fig. 3d). In line with our previous experiments, a similar series of studies performed with chloroquine yielded opposite results, confirming that autophagy blockade enhances $\mathrm{T}_{\mathrm{H}} 9$ cell differentiation (Fig. 3c, d).To test the possible effect of these drugs on proliferation and apoptosis, $\mathrm{T}_{\mathrm{H}} 9$ cells were stained with Ki67 or annexin $\mathrm{V}$ and 7-AAD. $\mathrm{T}_{\mathrm{H}} 9$ cells treated with chloroquine show a significant increase of apoptosis and a reduced proliferation compared to control cells (Supplementary Fig. 3). Metformin however did not affect cell death of differentiating $\mathrm{T}_{\mathrm{H}} 9$ cells but reduced their proliferation (Supplementary Fig. 3). Thus, chloroquine, despite its effects on $\mathrm{T}_{\mathrm{H}} 9$ cell proliferation and apoptosis, markedly enhances $\mathrm{T}_{\mathrm{H}}$ 9 cell IL-9 secretion on a per-cell basis, ultimately resulting in enhanced IL-9 secretion from chloroquine-treated $\mathrm{T}_{\mathrm{H}} 9$ cells (Supplementary Fig. 3). This overall supports the fact that the chloroquine-driven blockade of autophagy in $\mathrm{T}_{\mathrm{H}} 9$ cells supports their IL-9 secretion.

We have eventually tested the effects of chloroquine on human $\mathrm{T}_{\mathrm{H}} 9$ cell differentiation. For this, human $\mathrm{CD} 4 \mathrm{~T}$ cells were isolated from three different healthy blood donors and differentiated into $\mathrm{T}_{\mathrm{H}} 9$ cells in the presence or not of increasing doses of chloroquine. In line with our results obtained with mouse
T cells, we found that chloroquine enhanced IL-9 secretion from human $\mathrm{T}_{\mathrm{H}} 9$ cells in a dose-dependent manner (Fig. 3e). Collectively, although these results do not rule out any autophagy-independent effects of metformin and chloroquine on $\mathrm{T}_{\mathrm{H}} 9$ cell survival and proliferation, they strongly suggest that $\mathrm{T}_{\mathrm{H}} 9$ cell differentiation can be pharmacologically altered through the modulation of autophagy.

Autophagy blockade enhances PU.1 expression in $T_{H} 9$ cells. We next investigated the mechanism responsible for the modulation of $\mathrm{T}_{\mathrm{H}} 9$ cell functions by autophagy. Because autophagy deficiency was shown to alter the function of Treg cells through the induction of glycolysis ${ }^{16}$, we first monitored the phosphorylation of ribosomal protein S6 (pS6) and 4E-BP1, which denote the activation of the metabolic regulator mammalian target of rapamycin complex 1 (mTORC 1$)^{27}$, in differentiating control or Atg5fl/fl* $\mathrm{CD} 4$-CreTreg cells and $\mathrm{T}_{\mathrm{H}} 9$ cells. In contrast to Treg cells where we found enhanced phosphorylated pS6 and 4E-BP1 in the absence of Atg5 as recently reported ${ }^{16}$, the phosphorylation levels of these two proteins were similar in $\mathrm{T}_{\mathrm{H}} 9$ cells independently of Atg5 expression (Supplementary Fig. 4). Thus, contrary to Treg cells, there is no contribution of mTORC1 in the autophagy-driven modulation of $\mathrm{T}_{\mathrm{H}} 9$ cell functions. We next monitored the expression of different transcription factors involved in $\mathrm{T}_{\mathrm{H}} 9$ cell polarization in differentiating control or Atg $5 \mathrm{fl} / \mathrm{fl}^{\star} \mathrm{CD} 4$-Cre cells. Although the expression of Stat6, pStat6, IRF-4 and GATA-3 are not affected by autophagy deficiency, we noted that the expression of PU.1 protein, the $\mathrm{T}_{\mathrm{H}} 9$ cell master transcription factor encoded by Sfpi1 gene, was markedly enhanced in $\mathrm{T}_{\mathrm{H}} 9$ cells deficient for Atg5 compared to Atg5-expressing controls (Fig. 4a and Supplementary Fig. 5a, b, c). Accordingly, naive CD4 T cells differentiated into $\mathrm{T}_{\mathrm{H}} 9$ cells in the presence of metformin or chloroquine respectively featured repressed or enhanced levels of PU.1 protein compared to controls (Fig. 4b, c and Supplementary Fig. 5d). Importantly, Sfpil mRNA was unaffected by the presence of metformin or chloroquine during $\mathrm{T}_{\mathrm{H}} 9$ cell differentiation, suggesting a post-transcriptional effect of these drugs on PU.1 expression (Fig. 4d). Interestingly, the protein expression of the transcription factor GATA-3, which is essential for $\mathrm{T}_{\mathrm{H}} 9$ cell differentiation $^{28}$, was unaffected by metformin or chloroquine, indicating that autophagy selectively affects PU.1 protein expression (Fig. 4b, c). Because Sfpil mRNA levels did not significantly change prior to the corresponding protein, we hypothesized that autophagy regulates PU.1 expression posttranscriptionally. To test this, we differentiated naive WT CD4 $\mathrm{T}$ cells in the presence or not of chloroquine into $\mathrm{T}_{\mathrm{H}} 9$ cells for $16 \mathrm{~h}$ and subsequently inhibited transcription using 5,6-dichloro-1- $\beta$-D-ribofuranosylbenzimidazole (DRB) and assessed Sfpil mRNA expression after $8 \mathrm{~h}$. We found that, while DRB efficiently prevented Sfpil gene expression, it failed to block the chloroquine-induced enhanced expression of PU.1 protein (Fig. 4e, f and Supplementary Fig. 5e), indicating that the blockade of autophagy favours PU.1 expression in differentiating $\mathrm{T}_{\mathrm{H}} 9$ cells independently of transcription. We then tested whether autophagy affected the stability of PU.1 protein in differentiating $\mathrm{T}_{\mathrm{H}} 9$ cells. For this, we differentiated control or Atg $5 \mathrm{fl} / \mathrm{fl}^{\star} \mathrm{CD} 4$-Cre cells into $\mathrm{T}_{\mathrm{H}} 9$ cells for $16 \mathrm{~h}$ and subsequently blocked translation using cycloheximide and kinetically monitored PU.1 degradation by western blot. We found that the degradation of PU.1 was notably reduced in Atg5 $\mathrm{fl} / \mathrm{fl}{ }^{\star} \mathrm{CD} 4-\mathrm{Cre}$ cells compared to control cells, indicating that the absence of autophagy prolongs PU.1 protein half-life in $\mathrm{T}_{\mathrm{H}} 9$ cells. Indeed, the absence of Atg5 promotes PU.1 protein stability, enhancing its half-life from 3 to more than $6 \mathrm{~h}$ (Fig. $4 \mathrm{~g}, \mathrm{~h}$ and 


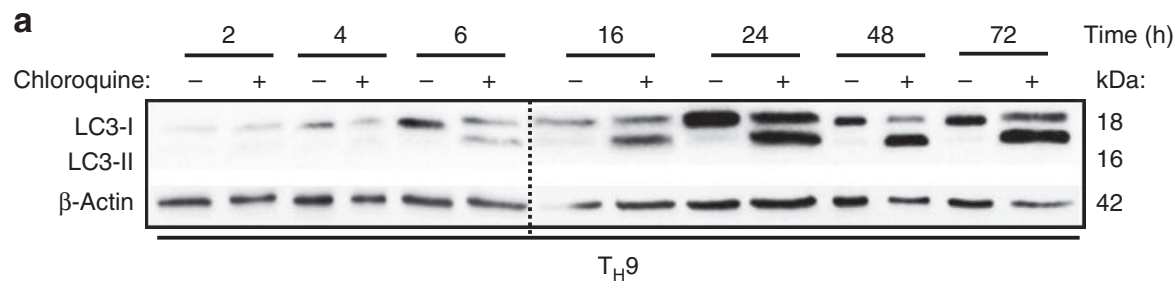

b

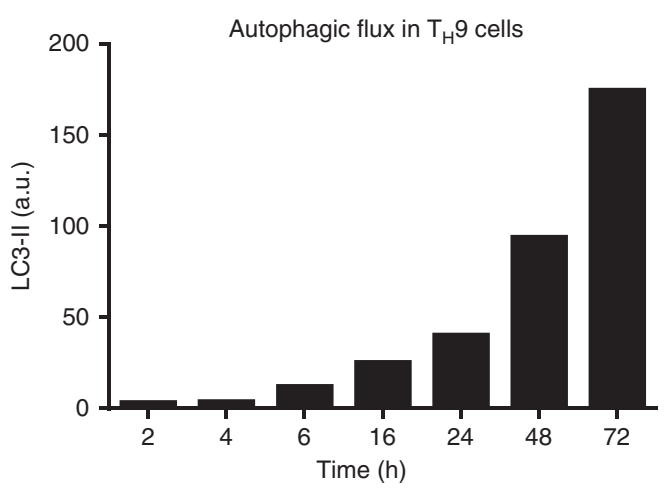

C

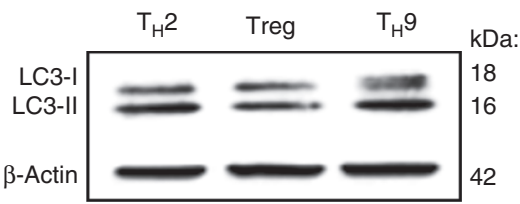

d

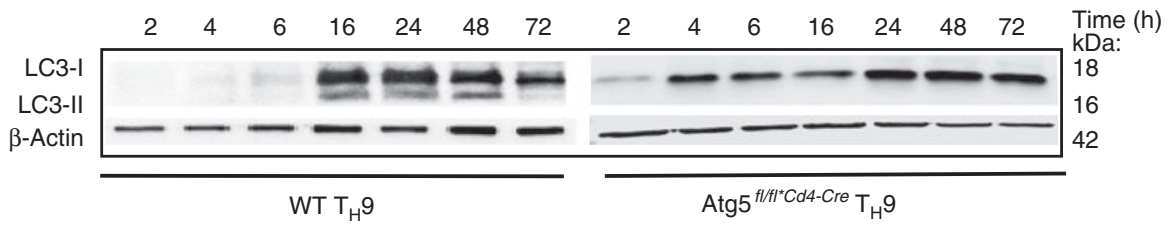

Fig. 2 Autophagy is active during $T_{H} 9$ cell differentiation. a The conversion from endogenous LC3-I to LC3-II, the autophagosome marker, during $T_{H} 9$ cell differentiation was monitored by western blot in the presence and absence of chloroquine. The amounts of LC3-II on this immunoblot were used to determine the autophagic flux in $T_{H} 9$ cells. $\mathbf{b}$ The autophagic flux during $T_{H} 9$ cell differentiation was determined by calculating the differences in the amount of LC3-II between cells cultured with or without the lysosomal inhibitor chloroquine, thus representing the amount of LC3 that is delivered to lysosomes for degradation. c Immunoblot analysis of LC3-II expression in $T_{H} 2$, Treg and $T_{H} 9$ cells, differentiated for 3 days. d Western blot of LC3-II in Atg5-deficient cells compared to WT cells during $T_{H} 9$ cell differentiation

Supplementary Fig. 5f). To investigate the subcellular localization of PU.1 protein during $\mathrm{T}_{\mathrm{H}} 9$ cell differentiation we performed a kinetic experiment in $\mathrm{T}_{\mathrm{H}} 9$ cells from WT and Atg5-deficient mice followed by a subcellular fractionation. The expression of PU.1 was then analysed in nuclear and cytoplasmic fractions by western blot. In WT $\mathrm{T}_{\mathrm{H}} 9$ cells, PU.1 is mainly nuclear with an important nuclear expression from 8 to $48 \mathrm{~h}$ of differentiation, according to its function as transcription factor and master regulator of the $\mathrm{T}_{\mathrm{H}} 9$ programme. Interestingly, in the absence of Atg5, PU.1 protein expression is higher in both fractions compared to WT cells (Supplementary Fig. 6). PU.1 can be easily detected in the nuclear and cytoplasmic fractions of the cells from $8 \mathrm{~h}$ of differentiation (Supplementary Fig. 6). Overall, these results demonstrate that preventing autophagy in $\mathrm{T}_{\mathrm{H}} 9$ cells leads to enhanced stability of the $\mathrm{T}_{\mathrm{H}} 9$ cell transcription factor PU.1.

Selective autophagy targets PU.1 for degradation. P62 protein, a selective autophagy adaptor, is removed from the cytoplasm upon autophagy $6,29,30$. This process is responsible for the selective degradation of proteins that bind to $\mathrm{p} 62^{6}, 29,30$. Because our observations indicated a selective degradation of
PU. 1 in $\mathrm{T}_{\mathrm{H}} 9$ cells, we have interrogated the contribution of p62-dependent selective autophagy in $\mathrm{T}_{\mathrm{H}} 9$ cell differentiation. For this, we first monitored p62 and PU.1 expression during the course of $\mathrm{T}_{\mathrm{H}} 9$ cell differentiation. Western blot analysis showed that $\mathrm{p} 62$ expression was induced in $\mathrm{T}_{\mathrm{H}} 9$ cells and peaked $16 \mathrm{~h}$ after the initiation of differentiation (Figs. 5a, b and Supplementary Fig. 7). As a selective autophagy adaptor, p62 is known to be degraded through autophagy, 29,30 . Accordingly, kinetic monitoring of the total cellular expression levels of p62 inversely correlates with the autophagic activity during the course of $\mathrm{T}_{\mathrm{H}} 9$ cell differentiation (Fig. $5 \mathrm{c}$ ), thereby suggesting that in $\mathrm{T}_{\mathrm{H}} 9$ cells p62 is also degraded through autophagy.

Because PU.1 is selectively degraded during $\mathrm{T}_{\mathrm{H}} 9$ differentiation, we next tested the putative interaction between PU.1, LC3-II and p62 in $\mathrm{T}_{\mathrm{H}} 9$ cells. For this, we first used a proximity ligation assay (PLA). We found that PU.1 interacts with LC3-II and p62 in $\mathrm{T}_{\mathrm{H}} 9$ cells, whereas no PLA foci were detected with control antibodies (Fig. 5d, e). Moreover, we also checked by PLA if other $\mathrm{T}_{\mathrm{H}} 9$ transcription factors are recruited by p62 and found no interaction for Stat 6 or GATA-3 and a weak interaction for IRF-4 compared to PU.1 suggesting that, in $\mathrm{T}_{\mathrm{H}} 9$ cells, PU.1 is 

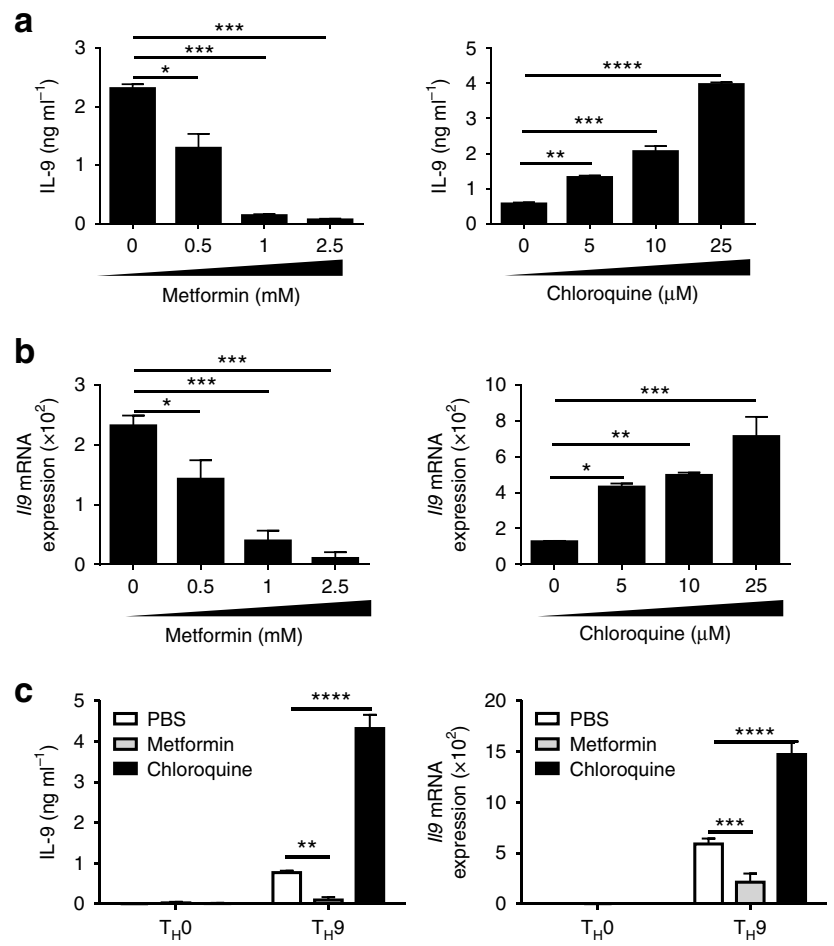

d
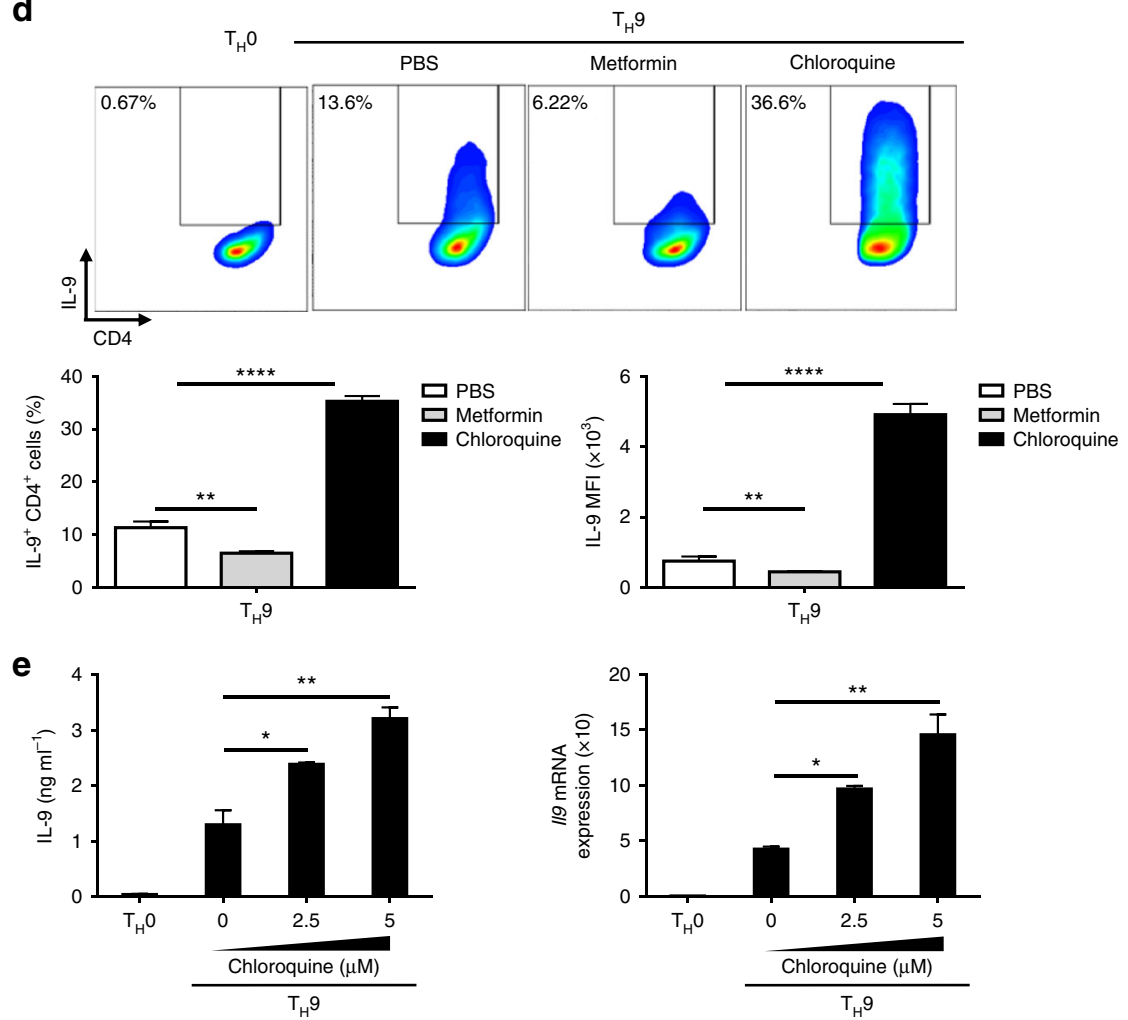

Fig. 3 Mouse and human $T_{H} 9$ cell differentiation can be pharmacologically altered through modulation of autophagy. $\mathbf{a}$, $\mathbf{b}$ Wild-type mouse naive $C D 4^{+} T$ cells were differentiated into $T_{H} 9$ cells with increasing doses of metformin or chloroquine and then IL-9 secretion levels were determined by ELISA and qRT-PCR after a 3-day culture. GRT-PCR results were normalized to the expression of Actb. Data are representative of three experiments. Naive CD4 ${ }^{+} \mathrm{T}$ cells were isolated from IL-9-EGFP mice and differentiated into $T_{H} 9$ cells for 3 days in the presence of metformin $(1 \mathrm{mM})$ or chloroquine $(25 \mu \mathrm{M})$ and IL-9 expression was analysed by $\mathbf{c}$ ELISA, qRT-PCR and $\mathbf{d}$ flow cytometry. FACS plots are representative of three experiments. The frequencies and mean fluorescence intensity (MFI) of IL-9-expressing cells are depicted (right panels). e Naive human $\mathrm{CD}^{+}{ }^{+} \mathrm{T}$ cells were cell-sorted from three healthy blood donors and differentiated into $\mathrm{T}_{\mathrm{H}} 9$ cells in the presence of increasing doses of chloroquine. IL-9 expression was then analysed by ELISA and qRT-PCR, and results were normalized to the expression of $A c t b$ and are presented relative to control $\mathrm{T}_{\mathrm{H}} \mathrm{O}$ cells. One representative experiment with one donor is shown. Data are representative of three experiments. Mean (+s.d.), NS, not significant with $P>0.05$; ${ }^{\star} P<0.05$; ${ }^{\star \star} P<0.01$; ${ }^{\star \star \star} P<0.001$; ${ }^{\star \star \star \star} P<0.0001$ two- way analysis of variance (ANOVA) test 
preferentially recruited by p62 (Supplementary Fig. 8a, b). Immunoprecipitation experiments confirmed the formation of a PU.1-p62 complex in $\mathrm{T}_{\mathrm{H}} 9$ cells treated in the presence of chloroquine (Fig. 5f and Supplementary Fig. 9a). Importantly, we also found that PU.1 was polyubiquitinated (Fig. $5 \mathrm{~g}$ and Supplementary Fig. 9b), which is an essential mark to target a protein for selective autophagy degradation. We next analysed the PU.1 complexes in $\mathrm{T}_{\mathrm{H}} 9$ cells treated with chloroquine by mass spectrometry. As previously described ${ }^{31}$, PU.1 interacts with other transcription factors, mRNA splicing factors and RNA binding proteins (Table 1 and Supplementary Fig. 8c), showing that PU.1 is part of different complexes, and hence suggesting a a

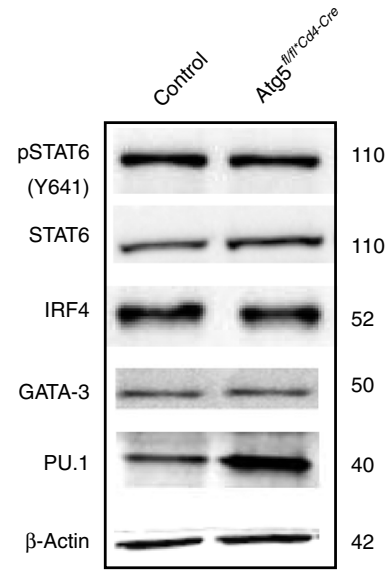

C

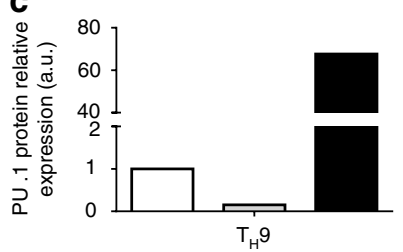

d

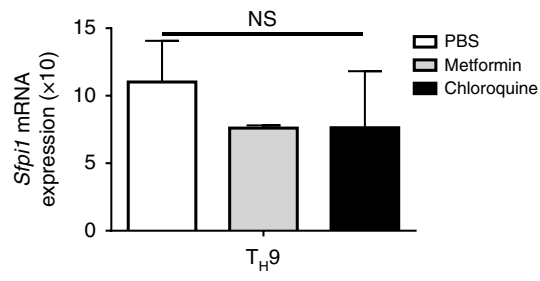

f

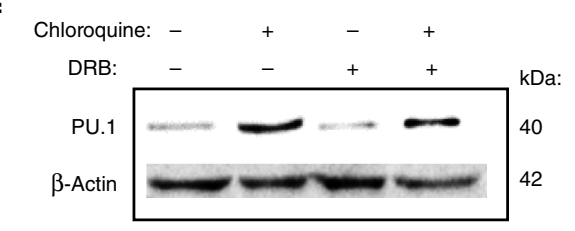

b
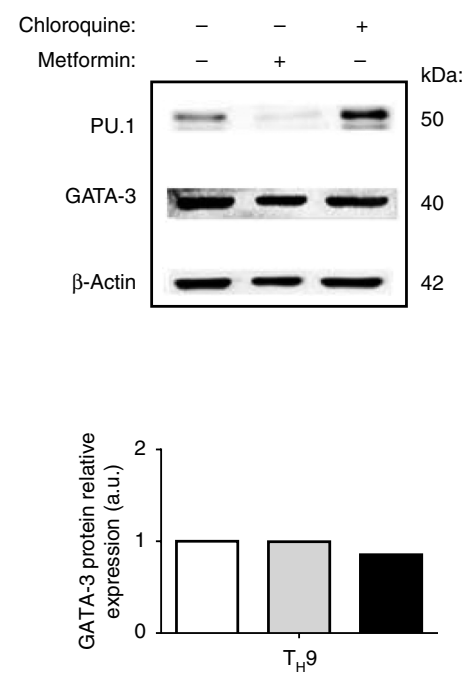

ㅁ PBS Metformin

e
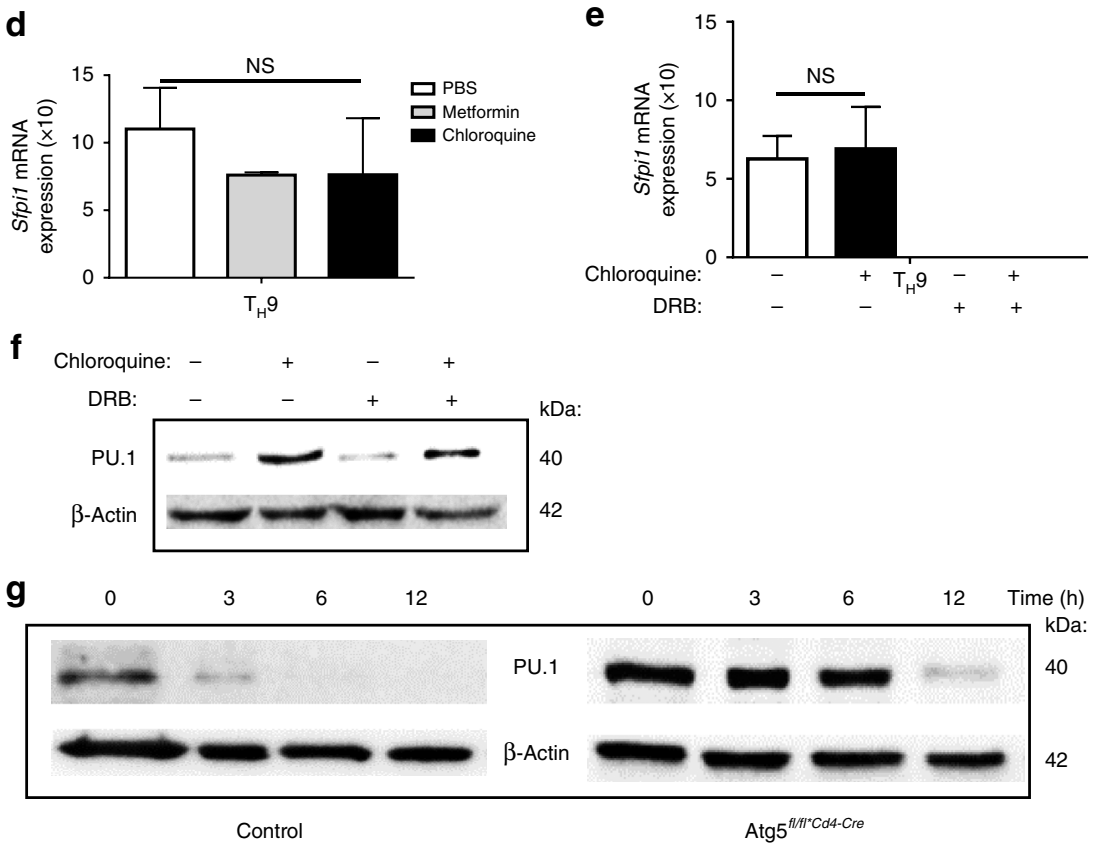

h PU.1 degradation in $\mathrm{T}_{\mathrm{H}} 9$ cells

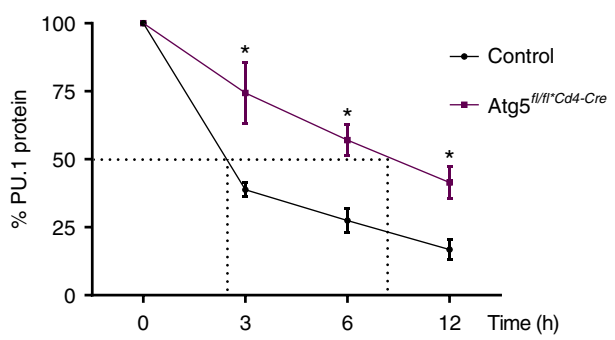


variety of functions for this transcription factor in $\mathrm{T}_{\mathrm{H}} 9$ cells. Importantly, mass spectrometry analysis of PU.1 complexes revealed that p62 interacts with PU.1 (Table 2). p62 is known to bind to polyubiquitinated protein cargos via an ubiquitinassociated (UBA) domain ${ }^{7}$, and to autophagy machinery via a LC3-interacting region (LIR), thus making a bridge between polyubiquitinated cargos and autophagosomes. To test whether p62 interacts with PU.1 through its UBA domain we used a coupled transcription/translation in vitro system to generate p62 proteins labelled with biotinylated lysine. We synthesized both full-length p62 (p62_FL) and p62 lacking the UBA domain (p62_UBA $\Delta$ ). These two proteins were subsequently incubated with total extracts from $\mathrm{T}_{\mathrm{H}} 9$ cells differentiated for $24 \mathrm{~h}$. The binding of endogenous PU.1 was tested in a pull-down assay and revealed using western blot analysis. Importantly, we found that UBA truncation significantly impaired p62 ability to recruit PU.1 without affecting its interaction with LC3-II (Fig. 5h, i and Supplementary Fig. 9c). Moreover, mass spectrometry analysis also reveals that PU.1 interacts with different K63 E3 ubiquitin ligases such as Ubr5, Hectd1 and Wwp2 (Table 2). As ubiquitination can target proteins for selective autophagydependent degradation with $\mathrm{K} 63$ ubiquitination ${ }^{32}$, we have assessed PU.1 ubiquitination by PLA and found enhanced PU.1 K63 ubiquitination in $\mathrm{T}_{\mathrm{H}} 9$ cells treated with chloroquine, suggesting that PU.1 is preferentially degraded through autophagy in $\mathrm{T}_{\mathrm{H}} 9$ cells (Fig. 5j). In line with this result, pharmacological inhibition of the proteasome with MG132, a proteasome inhibitor, failed to enhance PU.1 expression in differentiating $\mathrm{T}_{\mathrm{H}} 9$ cells, confirming that PU. 1 degradation in $\mathrm{T}_{\mathrm{H}} 9$ cells is primarily driven through autophagy (Supplementary Fig. 10). To test the relevance of p62-dependent degradation of PU.1 in $\mathrm{T}_{\mathrm{H}} 9$ cell differentiation, we silenced p62 expression in differentiating $\mathrm{T}_{\mathrm{H}} 9$ cells with a siRNA preventing p62 expression. In line with our hypotheses, we found that p62 inhibition shown by western blot enhanced $\mathrm{T}_{\mathrm{H}} 9$ cell differentiation as illustrated by enhanced IL-9 secretion (Fig. 5k, 1 and Supplementary Fig. 11a, b). Importantly, p62 inhibition led to increased PU.1 expression (Fig. 5m, n and Supplementary Fig. 11c). Altogether, these findings indicate that the p62-dependent degradation of the PU.1 transcription factor through selective autophagy represses $\mathrm{T}_{\mathrm{H}} 9$ cell differentiation.

Autophagy blockade enhances $\mathrm{T}_{\mathrm{H}} \mathbf{9}$ cell anticancer functions. We and others have shown that $\mathrm{T}_{\mathrm{H}} 9$ cells harbour superior anticancer properties compared to those of $\mathrm{T}_{\mathrm{H}} 1$ or $\mathrm{T}_{\mathrm{H}} 17$ cells upon adoptive transfer in vivo ${ }^{33}, 34$. Because we found that autophagy blockade can enhance $\mathrm{T}_{\mathrm{H}} 9$ cell differentiation, we have examined the ability of $\mathrm{T}_{\mathrm{H}} 9$ cells differentiated in conditions preventing autophagy to suppress melanoma tumour growth in vivo. For this, B16-OVA cells (ovalbumin (OVA)-transfected B16F10 melanoma cancer cells) were injected intravenously (i.v.) into C57BL/6 mice along with CD4 T cells isolated from OT-II mice, which have a TCR specific for the OVA peptide (323-339) presented by major histocompatibility complex class II molecules, treated ex vivo with chloroquine and polarized into $\mathrm{T}_{\mathrm{H}} 9$ cells. The enumeration of the number of lung tumour foci after 14 days revealed that chloroquine-treated $\mathrm{T}_{\mathrm{H}} 9$ cells featured enhanced anticancer effects over control $\mathrm{T}_{\mathrm{H}} 9$ cells (Fig. 6a). In addition, by using CD4 $\mathrm{T}$ cells from TCR transgenic mice recognizing tyrosinase-related protein 1 $(\mathrm{TRP}-1)^{35}$, a melanocyte differentiation antigen naturally expressed by B16F10 melanoma cells, we also found that the anticancer activity of $\mathrm{T}_{\mathrm{H}} 9$ cells was similarly enhanced by chloroquine in the non-OVA B16F10 tumour model (Fig. 6b). To further investigate the links between $\mathrm{T}_{\mathrm{H}} 9$ cells and autophagy in a cancer setting, we implanted B16-OVA tumour cells subcutaneously (s.c.) into control or Atg5fl/fl ${ }^{\star} \mathrm{CD} 4$-Cremice. We found that mice with selective Atg5 deficiency in CD4 $\mathrm{T}$ cells featured reduced tumour growth over controls (Fig. 6c). Importantly, anti-IL-9 antibody treatment abrogated the beneficial effect of autophagy deficiency in CD4 T cells, proving that the anticancer effect is driven by enhanced $\mathrm{T}_{\mathrm{H}} 9$ cell function (Fig. 6c). Similar results were noted in the MC38 colon adenocarcinoma tumour model (Fig. 6d). By analysing the B16OVA tumour infiltrate, we found enhanced frequency of IL-9producing CD4 tumour-infiltrating lymphocytes (TILs). In vitro stimulation of TILs with $\mathrm{OVA}_{323-339}$ peptide led to marked increase of IL-9 from stimulated CD4 TILs, as detected by ELISA and qPCR (Fig. 6e). IL-9 has been shown to favour CD8 T-cell activation in a model of pulmonary melanoma in mice ${ }^{36}$. Accordingly, tumour infiltrate analysis showed enhanced frequency of IFN- $\gamma$-producing CD8 TILs in our system. Moreover, in vitro stimulation of TILs with $\mathrm{OVA}_{257-264}$ peptide also led to marked increase of IFN- $\gamma$ from stimulated CD8 TILs as detected by ELISA and qPCR (Supplementary Fig. 12a). Finally, we obtained similar results with MC38 TILs from control or Atg5fl/fl ${ }^{\star} \mathrm{CD} 4-C r e$ mice (Fig. $6 \mathrm{f}$ and Supplementary Fig. 12b). Altogether, these results show that the suppression of autophagy in $\mathrm{T}_{\mathrm{H}} 9$ cells increases their ability to induce anticancer immune responses in vivo.

\section{Discussion}

In this study we show that induction of autophagy in effector CD4 $\mathrm{T}$ cells selectively represses $\mathrm{T}_{\mathrm{H}} 9$ cell differentiation through a p62-dependent degradation of the $\mathrm{T}_{\mathrm{H}} 9$ cell master transcription factor PU.1. Accordingly, CD4 T cells lacking Atg3, Atg5 or LC3-II feature increased IL-9 secretion relative to control cells upon differentiation into $\mathrm{T}_{\mathrm{H}} 9$ cells. Moreover, pharmacological blockade of autophagy using chloroquine enhances both mouse and human $\mathrm{T}_{\mathrm{H}} 9$ cell differentiation. During $\mathrm{T}_{\mathrm{H}} 9$ cell differentiation, the $\mathrm{T}_{\mathrm{H}} 9$ cell master transcription factor PU.1 is K63-ubiquitinated and recruited by p62, which targets PU.1 for degradation through selective autophagy. Finally, genetic or pharmacological blockade of autophagy in $\mathrm{T}_{\mathrm{H}} 9$ cells not only enhances their anticancer functions in an IL-9-dependent manner

\footnotetext{
Fig. 4 Autophagy modulates PU.1 protein stability in $\mathrm{T}_{\mathrm{H}} 9$ cells. a Naive $\mathrm{CD} 4^{+} \mathrm{T}$ cells were isolated from Atg5 $5^{f / /{ }^{*} \mathrm{CD} 4-\mathrm{Cre}}$ and $\mathrm{Atg} 5^{f l / f l^{*} \mathrm{CD} 4-\mathrm{Cre}} \mathrm{mice}$ and differentiated into $T_{H} 9$ cells for $24 \mathrm{~h}$. Representative western blot of $T_{H} 9$ cell-related transcription factors in Atg5-deficient $T_{H} 9$ cells compared to controls. Data are representative of two experiments. $\mathbf{b}$ Naive $C D 4^{+} \mathrm{T}$ cells were isolated and differentiated into $\mathrm{T}_{\mathrm{H}} 9$ cells for $24 \mathrm{~h}$ in the presence of metformin $(1 \mathrm{mM})$ or chloroquine $(25 \mu \mathrm{M})$. PU.1, GATA-3 and $\beta$-actin expression was analysed by western blot and its quantification is shown in $\mathbf{c}$. $\mathbf{d}$ Same as in $\mathbf{b}$ and Sfpil expression was determined by quantitative RT-PCR at $24 \mathrm{~h}$ from three experiments. e Naive CD4 ${ }^{+} \mathrm{T}$ cells were isolated and differentiated into $\mathrm{T}_{\mathrm{H}} \mathrm{9}$ cells for $16 \mathrm{~h}$ in the presence or absence of chloroquine $(25 \mu \mathrm{M})$. Then, cells were treated with $25 \mu \mathrm{g} \mathrm{ml}{ }^{-1}$ of DRB, an inhibitor of transcription, for $8 \mathrm{~h}$. Sfpil mRNA expression was analysed by qRT-PCR at 0 and $8 \mathrm{~h}$ of DRB treatment and $\mathbf{f}$ PU.1 expression was analysed by western blot at $8 \mathrm{~h}$ of DRB treatment. Experiments performed twice. All qRT-PCR results were normalized to the expression of Actb (mean+s.d.), NS, not significant, analysis of variance (ANOVA) test. $\mathbf{g}$ Naive CD4 ${ }^{+}$T cells were isolated from Atg $5^{f / /{ }^{*} C D 4-C r e}$ and Atg $5^{f / / f l^{*} C D 4-C r e}$ mice and differentiated into $T_{H} 9$ cells. PU.1 protein expression was assessed by western blot after being treated with $25 \mu \mathrm{g} \mathrm{ml}^{-1}$ cycloheximide to inhibit protein synthesis for 3,6 and $12 \mathrm{~h}$. PU.1 protein expression is plotted in $\mathbf{h}$ as a percentage of total PU.1 protein at time zero, and reflects the values obtained from western blot shown. The western blot shown is representative of two independent experiments. Mean (+s.d.), ${ }^{\star} P<0.05$ two-way ANOVA test
} 
a

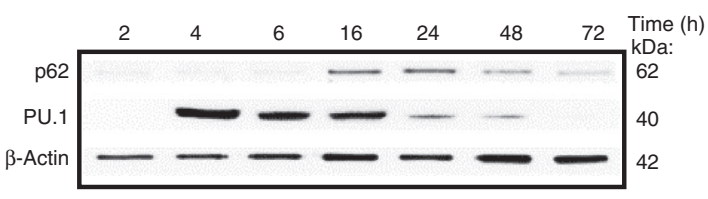

C
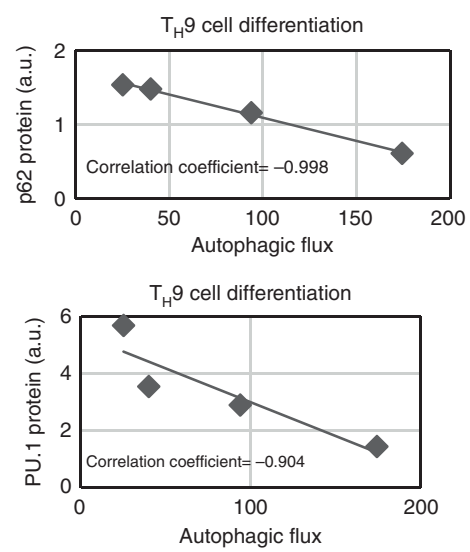

e

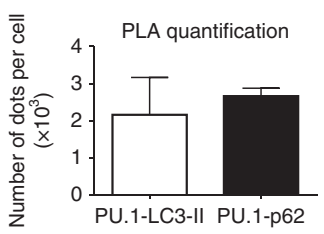

f

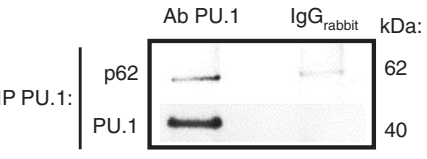

g

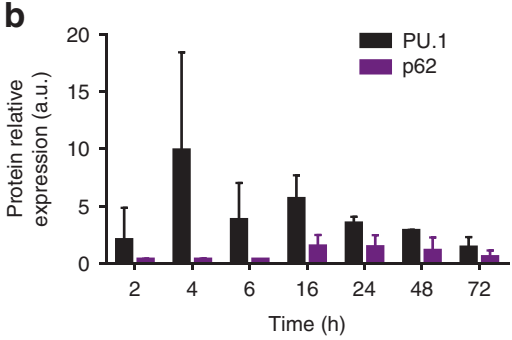

d
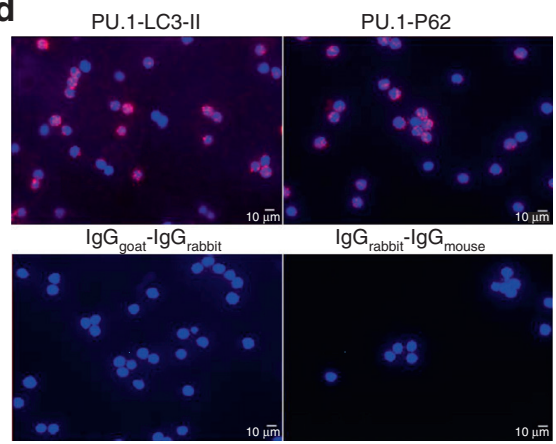

PolyUb-PU.1

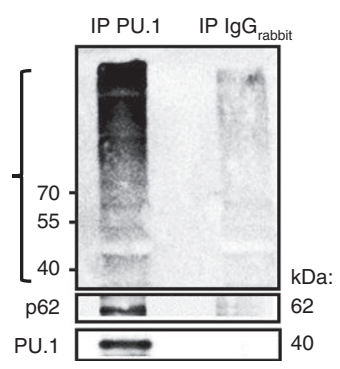

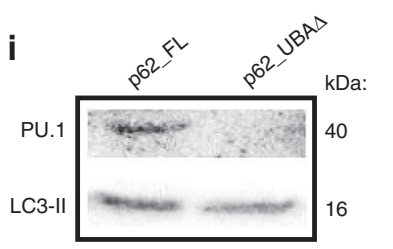

j
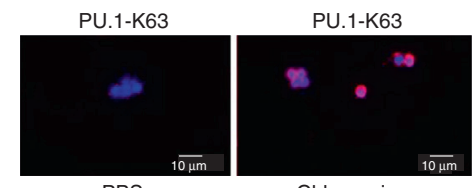

PBS

Chloroquine
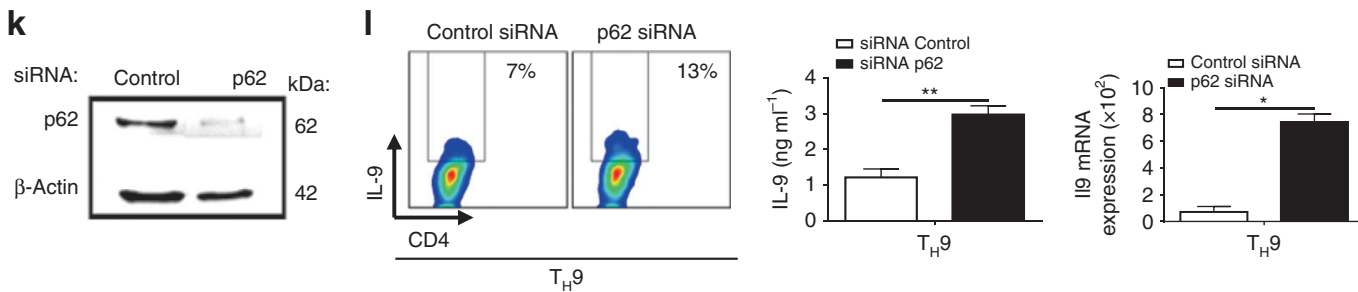

m
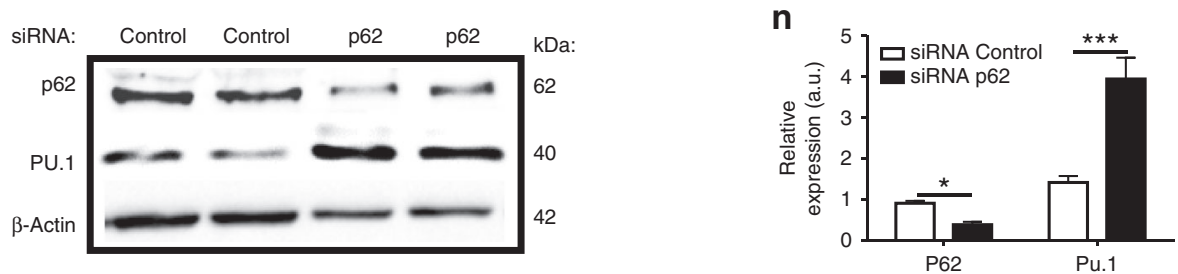

against melanoma upon adoptive transfer but also in vivo in both established colon cancer and melanoma.

$\mathrm{T}_{\mathrm{H}} 9$ cells were initially coined by Kuchroo and Stockinger laboratories as proinflammatory cells that contribute to tissue inflammation and defence against parasites ${ }^{28,37}$. Subsequently, this CD4 T-cell subset has gained further interest because of its potent anticancer properties, especially upon adoptive transfer into melanoma-bearing mice $33,34,38,39$. However, the regulation 
of $\mathrm{T}_{\mathrm{H}} 9$ cell development in the tumour microenvironment is still incompletely understood. We here demonstrate the biological importance of the regulation of $\mathrm{T}_{\mathrm{H}} 9$ cells by autophagy in tumours. Our results suggest that in the tumour microenvironment $\mathrm{T}_{\mathrm{H}} 9$ cells undergo increased autophagy leading to decreased IL-9 expression. While the tumour-derived factors affecting $\mathrm{T}_{\mathrm{H}} 9$ cell induction remain to be fully characterized, our findings may begin to explain the low abundance of $\mathrm{T}_{\mathrm{H}} 9$ cells in tumours and why they fail to drive complete tumour clearance in the absence of additional therapeutic intervention.

PU.1 is an ETS family transcription factor that is induced by transforming growth factor- $\beta$ (TGF- $\beta$ ) during $\mathrm{T}_{\mathrm{H}} 9$ cell differentiation and is essential for $\mathrm{T}_{\mathrm{H}} 9$ cell generation as illustrated by the inability of PU.1-deficient CD4 ${ }^{+} \mathrm{T}$ cells to produce IL-9 upon $\mathrm{T}_{\mathrm{H}} 9$ cell differentiation ${ }^{40}$. Interestingly, previous findings indicated that PU.1 selectively regulated IL-9 production in differentiating $\mathrm{T}_{\mathrm{H}} 9$ cells ${ }^{40}$. Our findings accordingly show that during $\mathrm{T}_{\mathrm{H}} 9$ cell differentiation the increased PU.1 protein level upon genetic or pharmacological inhibition of its degradation by autophagy enhances $\mathrm{T}_{\mathrm{H}} 9$ cell-derived IL-9, but not IL-10 or IL-21, secretion. Protein inclusions observed in the animal cells with defective autophagy are enriched in ubiquitin ${ }^{22}$. We similarly observed an accumulation of ubiquitinated PU.1 protein in $\mathrm{T}_{\mathrm{H}} 9$ cells treated with chloroquine. We also found that, through its UBA domain, p62 is able to bind ubiquitinated PU.1 and interacts with LC3-II. Our work thus suggests that PU.1 is selectively degraded during $\mathrm{T}_{\mathrm{H}} 9$ cell polarization through autophagy. While these results may contrast with previous studies indicating that PU.1 has a PEST domain and could thus be degraded by the proteasome, it is noteworthy that truncation of the PU.1 PEST domain did not lead to protein stabilization ${ }^{41}$, and treatments with proteasome inhibitors such as lactacystin only partially inhibited PU.1 degradation in F5-5 erythroblasts ${ }^{42}$. Eventually, we found that the differentiation of $\mathrm{T}_{\mathrm{H}} 9$ cells upon proteasome inhibition with MG132 failed to stabilize PU.1 protein, suggesting that in $\mathrm{T}_{\mathrm{H}} 9$ cells the degradation of PU.1 is predominantly driven through selective autophagy.

Chi and co-workers ${ }^{16}$ recently showed that autophagy affects the stability of Treg cells by coupling environmental cues and metabolic homeostasis. Here we show that autophagy can also impair $\mathrm{T}_{\mathrm{H}} 9$ cell stability but through an mTORC1-independent mechanism. Indeed, Atg5-deficient $\mathrm{T}_{\mathrm{H}} 9$ cells do not show increased mTORC1 activity. This observation suggests that autophagy can regulate CD4 T-cell biology in many ways that remain largely misunderstood. For instance, Kabat et al. ${ }^{43}$ elegantly reported how autophagy differentially regulates Treg and $\mathrm{T}_{\mathrm{H}} 2$ cells to control intestinal inflammation. They found that while Atg1611-deficient Treg cells showed significant decreased survival compared to WT Treg cells, Atg1611-deficient $\mathrm{T}_{\mathrm{H}} 2$ cells have increased survival. The authors attribute this observation to the sensitivity of $\mathrm{T}$ cells, which tend to shift from glycolysis when autophagy is affected to environmental perturbations in the autophagy pathway. Autophagy deficiency in Treg cells upregulates metabolic regulators and glycolysis, thus impairing Treg cell survival $^{16}$. In contrast to Treg cells, $\mathrm{T}_{\mathrm{H}} 2$ cells were shown to display an increased glycolytic rate ${ }^{44}$. This enhanced glycolytic metabolism used by $\mathrm{T}_{\mathrm{H}} 2$ cells makes them resistant to the metabolic changes triggered by autophagy deficiency. One important observation is that, like in $\mathrm{T}_{\mathrm{H}} 2$ cells, GATA-3 expression is essential for $\mathrm{T}_{\mathrm{H}} 9$ but not for Treg cell differentiation $^{28}$. Meanwhile, expression of Gata3 is linked to induction of glycolysis after TCR activation in T cells and orchestrates essential metabolic adaptations enforced by autophagy deficiency ${ }^{45}$. Thus, differential expression of factors such as GATA-3 may lead to different metabolic responses in the absence of autophagy in $\mathrm{CD} 4 \mathrm{~T}$ cells and explain why $\mathrm{T}_{\mathrm{H}} 9$ cells behave like $\mathrm{T}_{\mathrm{H}} 2$ cells regarding glycolysis.

Autophagy is essential to control inflammation ${ }^{46-48}$ this is exemplified by the ability of the amino acid sensor GCN2 to control gut inflammation through autophagy induction in CD11c antigen-presenting cells as well as epithelial cells, resulting in the repression of $\mathrm{T}_{\mathrm{H}} 17$ cell responses ${ }^{49}$. In humans, polymorphisms in several autophagy-related genes, including IRGM, LRRK2, SMURF1 and ATG16L1, leading to autophagy deficiency are linked to inflammatory bowel disease (IBD) susceptibility ${ }^{50}$. Crohn's disease and ulcerative colitis (UC) are the two most common forms of IBD. Strikingly, recent studies have shown an important function of $\mathrm{T}_{\mathrm{H}} 9$ cells in driving UC. $\mathrm{T}_{\mathrm{H}} 9$ cells expressing PU.1 were found in the gut mucosa of patients with UC as well as target cells expressing IL-9 receptor in the intestinal epithelium of IBD patients, suggesting that $\mathrm{T}_{\mathrm{H}} 9$ cells are relevant for the pathogenesis of IBD in humans ${ }^{51}$, 52. Moreover, $\mathrm{T}_{\mathrm{H}} 9$ transcription factor PU.1 and IL-9 expression were shown to be crucial for the development of experimental colitis in two different mouse models ${ }^{28}, 53$. Our findings that autophagy induction in $\mathrm{T}_{\mathrm{H}} 9$ cells reduces PU.1 stability and represses $\mathrm{T}_{\mathrm{H}} 9$ cell differentiation therefore suggest that autophagy prevents Th9 cell differentiation to limit inflammation.

Given the strong effector functions harboured by $\mathrm{T}_{\mathrm{H}} 9$ cells, we believe that the identification of autophagy as a factor dictating IL-9 secretion from $\mathrm{T}_{\mathrm{H}} 9$ cells provides significant insights to design new therapies not only against cancer but also to alleviate the course of allergic and autoimmune diseases. Moreover, these findings may have implications for the consideration of chloroquine for antitumour immunotherapy. Given the strong

Fig. 5 PU.1 protein is recruited by p62 and LC3-II and targeted for selective autophagy degradation in $T_{H} 9$ cells. a The expressions of p62 and PU.1 were analysed by western blot at different time points during $T_{H} 9$ cell differentiation. The western blot shown is representative of two independent experiments. b Quantification of the western blot shown in a. c Scatterplot showing the negative correlation between the amount of p62 or PU.1, determined by the western blot in a and the autophagic flux (determined in Fig. 2b). d Proximity ligation assay (PLA) showing the interaction between PU.1, LC3-II and p62 in $\mathrm{T}_{\mathrm{H}} 9$ cells, as well as control antibodies, after $24 \mathrm{~h}$ of differentiation. e PLA quantification: number of dots per cell out of 100 cells in two independent experiments. $\mathbf{f} I$ mmunoblot corresponding to co-immunoprecipitation experiment showing interaction of endogenous PU.1 and p62 in chloroquine-treated $\mathrm{T}_{\mathrm{H}} 9$ cells $(25 \mu \mathrm{M})$ after $24 \mathrm{~h}$ of differentiation. Shown is a typical experiment out of three. $\mathbf{g}$ Immunoblot corresponding to immunoprecipitation performed with anti-PU.1 antibody, followed by western blot detection using poly- and monoubiquitination antibody to examine the presence of poly-ubiquitinated PU.1 in chloroquine-treated $\mathrm{T}_{\mathrm{H}} 9$ cells $(25 \mu \mathrm{M})$ after $24 \mathrm{~h}$ of differentiation. $\mathbf{h}$ Schematic representation of the p62 cDNA fragments used for pull-down experiments. i Synthetic full-length p62 (p62_FL) and p62 lacking the UBA domain (p62_UBA $\Delta$ ) proteins were generated. These two proteins were subsequently incubated with total extracts from $T_{H} 9$ cells differentiated for $24 \mathrm{~h}$. The binding of endogenous PU.1 and LC3-II was tested in a pull-down assay and revealed using western blot analysis. Experiment performed twice. $\mathbf{j}$ PLA showing that in chloroquine-treated $\mathrm{T}_{\mathrm{H}} 9$ cells, PU.1 K63 ubiquitination can be detected after $24 \mathrm{~h}$ of differentiation. $T_{H} 9$ cells transfected with control siRNA or p62 siRNA. $\mathbf{k}$ p62 inhibition was assessed by western blot $48 \mathrm{~h}$ after transfection. I IL-9 expression was analysed by flow cytometry, ELISA and qRT-PCR after $72 \mathrm{~h}$ of differentiation. Shown is a typical experiment out of three. ${ }^{\star} P<0.05$; ${ }^{\star \star} P<0.01$ unpaired Student's $t$-test. $\mathbf{m}, \mathbf{n}$ p62 inhibition and PU.1 protein expression were assessed by western blot $48 \mathrm{~h}$ after transfection and quantified. Mean (+s.d.). Shown is a typical experiment out of three. ${ }^{\star} P<0.05$; ${ }^{\star \star \star} P<0.001$ two-way analysis of variance (ANOVA) test 
Table 1 Characterization of PU.1 complexes in $T_{H} 9$ cells Transcription factor mRNA splicing factor Translation factor

Maff

Med12I

Zfp648

Lsm3

Snrnp70

Wdr62

Stat1

Rbm22

Trappc2

Srsf11

Pdlim5

Pdlim1

Zbtb25

Naca

Rsf1

$\mathrm{Nr} 3 \mathrm{c} 1$

Cnot2

Psip1

Crtc3

Gtf2e1

Stat4

Ncor1

Lrrfip1

Tbp

Ctcf

Ddi1

Lima1

Zyx

Trip4

Gtf2f1

p300

Stat3

Mass spectrometry analysis of PU.1 complexes in $\mathrm{T}_{\mathrm{H}} 9$ cells treated with chloroquine $(25 \mu \mathrm{M})$ for $24 \mathrm{~h}$. The table shows a short list of PU.1 partners that belong to transcription, splicing and translation machineries

antitumour activity of $\mathrm{T}_{\mathrm{H}} 9$ cells in vivo, our findings could also be exploited for the adoptive T-cell therapy of cancer.

\section{Methods}

Mouse strains. All animals were bred and maintained according to both the FELASA (Federation of European Laboratory Animal Science Associations) and the Animal Experimental Ethics Committee Guidelines (University of Burgundy, Dijon, France and Zhejiang University, Hangzhou, China). Animals were used between 6 and 12 weeks of age. Female C57BL/6 mice were purchased from Charles River Laboratories (France) and Joint Ventures Slipper BK Experimental Animal (Shanghai, China). Mice were housed in specific pathogen-free facilities, and the experimental protocols were approved by the Animal Care and Use Committee of School of Medicine, Zhejiang University (Hangzhou, China) and of University of Burgundy (Dijon, France). Whenever required, animals were euthanized by $\mathrm{CO}_{2}$ exposure. TCR transgenic mice in which $\mathrm{CD}^{+} \mathrm{T}$ cells recognize OVA-derived antigen (OT-II) were provided by the CDTA (Cryopréservation, Distribution, Typage et Archivage animal, Orléans, France). TCR transgenic mice in which $\mathrm{CD} 4^{+} \mathrm{T}$ cells recognize the TRP- 1 antigen ${ }^{35}, \mathrm{CD} 4$-Cre mice and Atg $5^{\mathrm{fl} / \mathrm{fl}}$ mice were respectively purchased from JAX (stock numbers 8684 and 17336) and RIKEN (RBRC02975). Floxed Atg3 mice and ER-Cre mice were kindly provided by P. Youwen He (Duke University). Atg $3^{\mathrm{fl} / \mathrm{fl}}$ mice were bred with ER-Cre mice to generate Atg $3^{\mathrm{f} / \mathrm{fl}} \mathrm{ER}$-Cre mice. To induce Atg3 deficiency Atg $3^{\mathrm{f} / \mathrm{fl}}$ ER-Cre mice were intraperitoneally (i.p.) injected with $100 \mu$ g tamoxifen (Sigma) for 3 consecutive days. LC3-B-deficient mice were kindly provided by Professor Zhihua Chen (Zhejiang University). IL-9-EGFP mice ${ }^{26}$ were provided by Professor Richard Flavell. All transgenic mice used were on a C57BL/6 background and were age-matched with WT controls for experiments. Male mice were used for experiments using mice having CD4 T cells recognizing the TRP-1 antigen. Otherwise, female mice were used.

Tumour growth experiments. B16F10, B16-OVA melanoma and MC38 colon adenocarcinoma cells were cultured at $37^{\circ} \mathrm{C}$ under $5 \% \mathrm{CO}_{2}$ in RPMI- 1640 with glutamax-1 (Lonza) supplemented with $10 \%$ (vol/vol) fetal calf serum (Lonza), $1 \%$ penicillin, streptomycin, amphotericin B (Gibco), $4 \mathrm{mM}$ HEPES (Gibco) and $1 \mathrm{mM}$ sodium pyruvate (Gibco). B16-OVA and MC38 cells were kindly provided by Dr Rosenblatt (University of Miami Miller School of Medicine, Miami, FL, USA) and Professor Smyth (QIMR Berghofer Medical Research Institute, Brisbane, Australia), respectively. B16F10 cells were obtained from ATCC. All cells were routinely tested for mycoplasma contamination using Mycoalert Mycoplasma
Table 2 PU.1 complexes are associated with selective autophagy machinery

\begin{tabular}{llll} 
Gene symbol & Peptide & XCorr & $\boldsymbol{\Delta}$ Corr \\
\hline Ube2n & K.LELFLPEEYPM ${ }^{\star}$ AAPK.V & 2.811 & 0.248 \\
Ubr5 & K.NSLEDLTAEDFR.L & 3.303 & 0.476 \\
Hectd1 & R.DLVDKGGDIFLDQLAR.L & 3.046 & 0.135 \\
Wwp2 & R.LYIIM ${ }^{\star}$ R.G & 2.13 & 0.105 \\
Huwe1 & R.LLSLISIALPENK.V & 3.185 & 0.448 \\
Mib1 & R.AVHHAAFGDEGAVIEVLHR.G & 2.922 & 0.207 \\
Ube20 & K.SGYPDIGFPLFPLSK.G & 2.231 & 0.392 \\
Trim33 & K.SLLQQLENVTK.E & 2.823 & 0.27 \\
Rnf138 & R.ALDLENIM*R.R & 2.362 & 0.145 \\
Sqstm1 & K.NYDIGAALDTIQYSK.H & 3.524 & 0.503
\end{tabular}

Mass spectrometry analysis of PU. 1 complexes in $T_{H} 9$ cells treated with chloroquine $(25 \mu \mathrm{M})$ for $24 \mathrm{~h}$. Table showing some PU.1 partners such as p62 (Sqstm1) and different E3 ubiquitin ligases, the corresponding peptides as well as their associated XCorr (cross correlation) and $\Delta$ Corr the corresponding peptides
(delta correlation) scores

Detection Kit (Lonza, LT07-318) and found negative. $1 \times 5.10^{5}$ B16-OVA or $1 \times 10^{6}$ MC38 cells were injected s.c. into mice. In vivo IL-9 neutralization was achieved by i.p. injection (10 $\mathrm{mg}$ per $\mathrm{kg}$ body weight) of anti-IL-9 neutralizing antibody (MM9C1; BioXcell) on days -1 and 0 and twice a week following tumour implantation. As control we used control mouse IgG2a (in Vivo mAb Mouse IgG2a Isotype Control BioXcell BE0085). Tumour size was measured three times a week during 20 days following tumour implantation using a calliper. Animals with ulcerated tumours or with tumours above $300 \mathrm{~mm}^{2}$ in size were killed for ethical reasons. TILs were prepared by enzyme digestion with $1 \mathrm{mg} \mathrm{ml}^{-1}$ collagenase (Roche), $0.5 \mathrm{mg} \mathrm{ml}^{-1}$ DNase I and $25 \mu \mathrm{g} \mathrm{ml}^{-1}$ hyaluronidase (Sigma-Aldrich) at $37^{\circ} \mathrm{C}$ for $30 \mathrm{~min}$, followed by Percoll (GE Healthcare) gradient purification and analysed by flow cytometry, ELISA and qRT-PCR after stimulation with OVA (323-339) or OVA (257-264) peptides (Proimmune) at a final concentration of $10 \mu \mathrm{g} \mathrm{ml}^{-1}$ and $20 \mu \mathrm{g} \mathrm{ml}^{-1}$ respectively for the B16-OVA tumour model. For the MC38 in vivo model, TILs were stimulated with $50 \mathrm{ng} \mathrm{ml}^{-1}$ of phorbol 12-myristate 13-acetate (PMA) (Sigma-Aldrich) and $1 \mu \mathrm{g} \mathrm{ml}^{-1}$ of ionomycin (Sigma-Aldrich).

Alternatively, $5 \times 10^{5}$ B16-OVA and $2 \times 10^{6}$ effector OT-II $\mathrm{T}_{\mathrm{H}} 9$ cells differentiated in the presence or in the absence of chloroquine $(20 \mu \mathrm{M})$ were injected i.v. into C57BL/6 mice. Lung tumour foci were enumerated after 14 days in a blinded fashion. Similarly, $5 \times 10^{5}$ B16F10 and $5 \times 10^{4}$ effector TRP- $1 \mathrm{~T}_{\mathrm{H}} 9$ cells differentiated in the presence or in the absence of chloroquine $(20 \mu \mathrm{M})$ were injected i.v. into mice. Lung tumour foci were enumerated after 14 days in a blinded fashion.

In vitro T-cell differentiation. Naive $\mathrm{CD} 4^{+} \mathrm{T}$ cells $\left(\mathrm{CD} 4^{+} \mathrm{CD} 62 \mathrm{~L}^{\mathrm{hi}} \mathrm{CD} 44^{\mathrm{lo}}\right)$ were obtained from spleens and lymph nodes of mice. Isolated naive $\mathrm{T}$ cells were routinely $98 \%$ pure. $\mathrm{CD} 4^{+} \mathrm{T}$ cells were purified from spleen and lymph nodes with anti-CD4 microbeads (Miltenyi Biotec), and then were further sorted as naive CD4 ${ }^{+} \mathrm{CD} 62 \mathrm{~L}{ }^{\text {hi }} \mathrm{T}$ cells by flow cytometry with antibodies anti-CD4-FITC (RM4-4, BD Biosciences) and anti-CD62L-Alexa 700 (MEL-14, BD Biosciences). Isolated naive $\mathrm{CD}^{+} \mathrm{T}$ cells were stimulated with plate-bound antibodies against CD3 (145-2C11, $2 \mu \mathrm{g} \mathrm{ml}^{-1}$, BioXcell) and CD28 (PV-1, $2 \mu \mathrm{g} \mathrm{ml}^{-1}$, BioXcell) and polarized into effector $\mathrm{CD}^{+} \mathrm{T}$ lymphocyte subsets without cytokines ( $\mathrm{T}_{\mathrm{H}} 0$ cells), or with IL-12 $\left(20 \mathrm{ng} \mathrm{ml}^{-1}\right)$ for $\mathrm{T}_{\mathrm{H}} 1$ cells, or with IL-4 $\left(20 \mathrm{ng} \mathrm{ml}^{-1}\right)$ for $\mathrm{T}_{\mathrm{H}} 2$ cells, or with TGF- $\beta$ $\left(2 \mathrm{ng} \mathrm{ml}^{-1}\right)$ and IL-6 $\left(25 \mathrm{ng} \mathrm{ml}^{-1}\right)$ for $\mathrm{T}_{\mathrm{H}} 17$ cells, or with mouse TGF- $\beta\left(2 \mathrm{ng} \mathrm{ml}^{-1}\right)$ and IL-4 $\left(20 \mathrm{ng} \mathrm{ml}^{-1}\right)$ for $\mathrm{T}_{\mathrm{H}} 9$ cells. In some experiments, metformin or chloroquine were added (Sigma-Aldrich, France). Cells were classically harvested on day 3 (unless otherwise specified) for detection of cytokines by ELISA and RT-qPCR analysis. For human in vitro T-cell differentiation, naive T cells were sorted from healthy donors and stimulated with plate-bound antibodies against CD3 $\left(5 \mu \mathrm{g} \mathrm{ml}^{-1}\right.$, BioXcell $)$ and CD28 $\left(5 \mu \mathrm{g} \mathrm{ml}^{-1}\right.$, BioLegend $)$ and polarized into $\mathrm{T}_{\mathrm{H}} 9$ cells with TGF- $\beta\left(10 \mathrm{ng} \mathrm{ml}^{-1}\right)$ and IL-4 $\left(5 \mathrm{ng} \mathrm{ml}^{-1}\right)$ (R\&D systems).

siRNA transfection. Transient transfection of naive $\mathrm{CD} 4^{+} \mathrm{T}$ cells was performed in vitro using Lipofectamin RNAiMAX (Invitrogen, Carlsbad, CA, USA) according to the manufacturer's instructions. $5 \times 10^{5}$ cells were plated in 96-well plates, and siRNAs were transfected at $25 \mathrm{nM}$ final concentration for $24 \mathrm{~h}$. Then, $24 \mathrm{~h}$ after transfection, $\mathrm{CD}^{+} \mathrm{T}$ cells were stimulated with plate-bound anti-CD3 and anti-CD28 antibodies, differentiated into $\mathrm{T}_{\mathrm{H}} 9$ cells as described above and cultured for an additional 24 or $72 \mathrm{~h}$ before analysis with Silencer Select Predesigned siRNA specific for murine Atg5 (ID: 161983, Ambion, Life Technologies) or murine sqtsm1 (siGENOME Mouse Sqstm1 ((18412) D-047628-03-0020 GE Healthcare, Dharmacon) or Silencer Negative Control No. 1 (Sigma SIC001). 

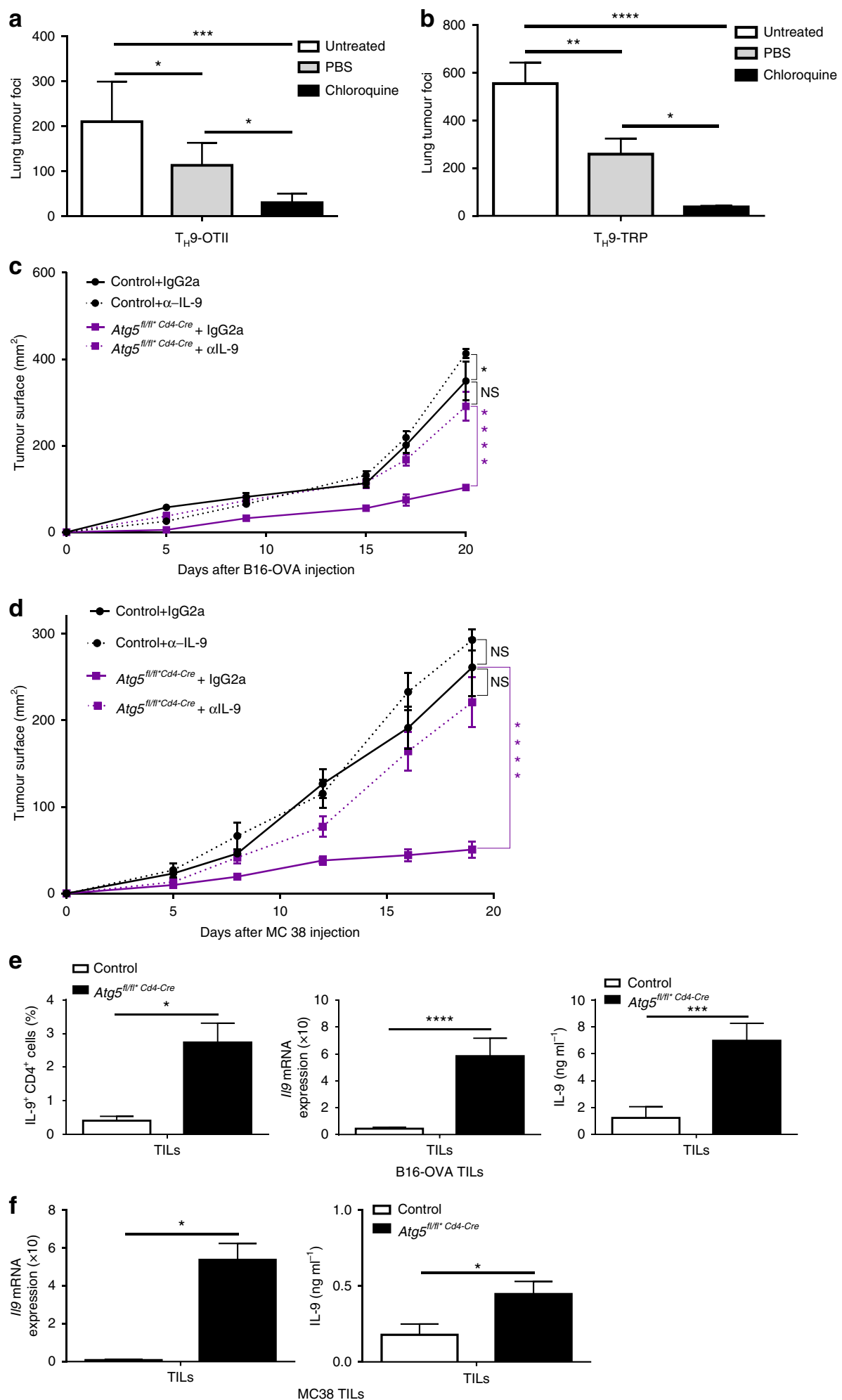

Fig. 6 Pharmacological and genetic blockade of autophagy in $T_{H} 9$ cells enhance their IL-9-dependent antitumour functions in vivo. a WT mice were injected i.V. with $0.5 \times 10^{6}$ B16-OVA melanoma cells and effector $2 \times 10^{6}$ OT-II $\mathrm{T}_{H} 9$ cells differentiated with or without chloroquine, and mean numbers of lung tumour foci are depicted (mean+s.d., 5 mice per group, 3 independent experiments). b WT mice were injected i.v. with $0.5 \times 10^{6}$ B16 melanoma cells and effector $0.1 \times 10^{6}$ TRP $T_{H} 9$ cells differentiated with or without chloroquine, and mean numbers of lung tumour foci are depicted (mean+s.d., 5 mice per group, 2 independent experiments). c, d Tumour growth (mean+s.e.m.) monitored three times a week, in B16-OVA or MC38 tumour-bearing control and Atg5 $5^{f / / f l^{*} \mathrm{CD} 4-\mathrm{Cre}}$ mice that received control mouse IgG2a or anti-IL-9 neutralizing antibodies (10 mg per kg body weight) at days -1 and 0 and then twice a week for 20 days (mean+s.e.m.) e TILs of B16-OVA tumour-bearing control and $\mathrm{Atg} 5^{\mathrm{fl} / \mathrm{fl} \mathrm{I}^{*} \mathrm{CD} 4-\mathrm{Cre}}$ mice isolated at day 20 after tumour cell injection and stimulated with ovalbumin peptides $\mathrm{OVA} \mathrm{A}_{323-339}$ for $24 \mathrm{~h}$. IL-9 expression from OVA O $_{323-339}$ CD4 stimulated TILs analysed by qPCR, ELISA and FACS. f MC38 TILs were stimulated with $50 \mathrm{ng} \mathrm{ml}^{-1}$ of PMA and $1 \mu \mathrm{mg}{ }^{-1}$ of ionomycin for $24 \mathrm{~h}$. IL-9 mRNA expression was analysed by qPCR and ELISA (mean+s.d., 5 mice per group, 2 independent experiments). NS, not significant with $P>0.05 ;{ }^{\star} P<0.05 ;{ }^{\star \star} P<0.01 ;{ }^{\star \star \star} P<0.001 ;{ }^{\star \star \star} P<0.0001$. a, b One-way analysis of variance (ANOVA) test; $\mathbf{c}, \mathbf{d}$ two-way ANOVA test; $\mathbf{e}, \mathbf{f}$ unpaired Student's $t$-test 
Retroviral infection of CD4 T cells. Retrovirus preparation was performed in Plat-E cells. Plat-E cells were transfected with $7.5 \mu \mathrm{g}$ pMX-IRES-GFP containing Cre gene, the media were replaced with fresh medium after $10 \mathrm{~h}$ and retrovirus supernatant was collected after additional $72 \mathrm{~h}$.

Naive CD4 T cells from Atg5 $5^{\mathrm{fl} / \mathrm{fl}}$ mice were stimulated with $2 \mu \mathrm{g} \mathrm{ml}^{-1}$ anti-CD3/CD28 overnight. Then, the retrovirus was added to the cells, followed by $4 \mathrm{~h}$ of incubation at room temperature and removal of the retrovirus. The $\mathrm{CD} 4 \mathrm{~T}$ cells were cultured in different $\mathrm{T}$ helper cell-polarized conditions for 5 days.

Measurement of cytokines. After $72 \mathrm{~h}$ of polarization, cell culture supernatants were assayed by ELISA for mouse IFN- $\gamma$, IL-4, IL-5, IL-13, IL-17 and IL- 9 (BioLegend) according to the manufacturer's protocol.

For intracellular staining, cells were cultured for 3 days, restimulated for 2 additional days and then stimulated for $4 \mathrm{~h}$ at $37^{\circ} \mathrm{C}$ in culture medium containing PMA (50 ng ml ${ }^{-1}$; Sigma-Aldrich) and ionomycin $\left(1 \mu \mathrm{g} \mathrm{ml}^{-1}\right.$; Sigma-Aldrich). After staining for surface markers and 7-AAD, cells were fixed and permeabilized according to the manufacturer's instructions (Cytofix/Cytoperm kit, BD Biosciences), and then stained for intracellular products. Monoclonal antibodies used for flow cytometry analyses were as follows: fluorescein isothiocyanate (FITC)-conjugated anti-CD4 (GK1.5, BD Biosciences, dilution 1:300), PC7conjugated CD8 (BD Biosciences, dilution 1:300), allophycocyanin (APC7)conjugated CD45 (BD Biosciences, dilution 1:300), Brilliant Violet (BV421)conjugated Foxp3 (BD Biosciences, dilution 1:100), phycoerythrin (PE)-conjugated IFN- $\gamma$ (BD Biosciences, dilution 1:300), PE-conjugated IL-4 (BD Biosciences, dilution 1:300), APC-conjugated anti-IL-9 (RM9A4, BioLegend, dilution 1:100) and APC-conjugated IL-17A (Pharmingen, dilution 1:300). All events were acquired by a BD LSR-II cytometer equipped with BD FACSDiva software (BD Biosciences) and data were analysed using FlowJo software (Tree Star, Ashland, OR, USA)

Cell lysis. RIPA lysis for western blot (WB): purified naive T cells were differentiated into $\mathrm{T}_{\mathrm{H}} 2, \mathrm{~T}_{\mathrm{H}} 9$ and Treg cells. Cell pellets were incubated in five volumes of RIPA buffer ( $50 \mathrm{mM}$ Tris- $\mathrm{HCl}$ ( $\mathrm{pH} 7.5$ ), $150 \mathrm{mM} \mathrm{NaCl}, 1 \% \mathrm{NP}-40$, $0.5 \%$ Nadeoxycholate, $0.1 \%$ sodium dodecyl sulfate, $1 \mathrm{mM}$ EDTA, protease inhibitors) for $45 \mathrm{~min}$ on ice. After centrifugation at $16,000 \times \mathrm{g}$ for $15 \mathrm{~min}$ at $4{ }^{\circ} \mathrm{C}$, the supernatant was recovered for WB analysis.

Low salt (LS) lysis for immunoprecipitation: purified naive $\mathrm{T}$ cells were differentiated for $24 \mathrm{~h}$ into $\mathrm{T}_{\mathrm{H}} 9$ cells in the presence or in the absence of chloroquine. Cell pellets were incubated in two volumes of LS buffer ( $10 \%$ glycerol, $20 \mathrm{mM}$ Tris- $\mathrm{HCl}$ ( $\mathrm{pH} 8$ ), $0.2 \mathrm{mM}$ EDTA, $0.1 \mathrm{M} \mathrm{KCl}, 0.5 \% \mathrm{NP}-40$, protease inhibitors) for $10 \mathrm{~min}$. Centrifugation at $16,000 \times \mathrm{g}$ for $15 \mathrm{~min}$ at $4{ }^{\circ} \mathrm{C}$ was used to recover the supernatant for immunoprecipitation analyses.

Protein concentration was assessed using the Bio-Rad DC protein assay kit. Proteins were then denaturated, loaded and separated on SDS-polyacrylamide gels and transferred on nitrocellulose membranes (Schleicher and Schuell). After blocking with $5 \%$ milk in phosphate-buffered saline and $0.1 \%$ Tween-20 (BST), membranes were incubated overnight with primary antibody diluted in BST washed and incubated for $1 \mathrm{~h}$ with secondary antibody diluted in BST/5\% milk. After additional washes, membranes were incubated with luminol reagent (Santa Cruz Biotechnology, Heidelberg, Germany) and exposed to Bio-Rad molecular imager ChemiDoc.

Immunoprecipitation. Total purified naive CD4 T cells were differentiated for $24 \mathrm{~h}$ into $\mathrm{T}_{\mathrm{H}} 9$ cells. Cell lysate was obtained by LS lysis as described above. Then, $1 \mathrm{ml}$ of protein lysate $(8 \mu \mathrm{g} / \mu \mathrm{l})$ was pre-cleared by incubation with $100 \mu \mathrm{l}$ of protein $\mathrm{A} / \mathrm{G}$ beads (Invitrogen) on a wheel for $1 \mathrm{~h}$ at $4{ }^{\circ} \mathrm{C}$. After $1 \mathrm{~min}$ of centrifugation at $400 \times g$ the lysate was recovered for the immunoprecipitation $\left(20 \mathrm{ml}\right.$ of pre-clear lysate corresponding to the input was conserved at $-20^{\circ} \mathrm{C}$ ). Next, $500 \mu \mathrm{l}$ of the pre-cleared lysate was incubated with $10 \mu \mathrm{g}$ of PU.1 antibody or control IgG rabbit antibody (Sigma) on a wheel for $2 \mathrm{~h}$ at $4{ }^{\circ} \mathrm{C}$. A total of $50 \mu \mathrm{l}$ protein $\mathrm{A} / \mathrm{G}$ beads were added before incubating on a wheel for $1 \mathrm{~h}$ at $4{ }^{\circ} \mathrm{C}$. Finally, the beads were collected by centrifugation, washed three times in LS buffer, and analysed by WB.

Protein pull-down by biotinylated $\mathbf{p 6 2}$ proteins. RT reactions were performed using The SuperScript III First-Strand Synthesis System (Life Technologies) and total RNA from $\mathrm{T}_{\mathrm{H}} 9$ cells at $24 \mathrm{~h}$ of differentiation. PaltinumTaq DNA polymerase high fidelity (Invitrogen) was used for PCR amplification of desired fragments corresponding to full-length p62 (p62_FL) and p62 lacking the UBA domain (p62_UBA $\Delta$ ). All forward primers had a T7 promoter sequence: $5^{\prime}$-taatacgactcactatagggaga- $3^{\prime}$ while reverse primer had a TAA stop codon. The primers were:

p62_FL: forward $5^{\prime}$-ataaaagctgggctctcggc- $3^{\prime}$; reverse: $3^{\prime}$-tcacaatggtggagggtgctt- $5^{\prime}$ and p62_UBA $\Delta$ : forward $5^{\prime}$-atggcgtcgttcacggtgaa- $3^{\prime}$; reverse: $3^{\prime}$-cttcagccctgtg ggtcctt-5'

Synthetic p62_FL and p62_UBA $\Delta$ proteins were then generated using TnT Quick Coupled Transcription/Translation Systems (Promega L1170) combined with biotinylated lysine (Transcend tRNA Promega L5061) according to the manufacturer's instructions. These two proteins were subsequently incubated with total extracts from $\mathrm{T}_{\mathrm{H}} 9$ cells differentiated for $24 \mathrm{~h}$ for pull-down assay. For this we used the Pierce Pull-down Biotinylated-protein: protein interaction kit (Thermo Scientific 21115) according to the manufacturer's instructions. The binding of endogenous PU.1 and LC3-II was revealed by western blots.

Cell fractionation. $1 \times 10^{6} \mathrm{~T}_{\mathrm{H}} 9$ cells differentiated for $8,16,48$ and $72 \mathrm{~h}$ were pelleted at 1,800 r.p.m. for $5 \mathrm{~min}$. The pellet was resuspended in $50 \mu \mathrm{l}$ of buffer A (10 mM KCl, $20 \mathrm{mM}$ HEPES (pH 7.5), $1.5 \mathrm{mM} \mathrm{MgCl}_{2}, 1 \mathrm{mM}$ EDTA, 1 mM EGTA, $250 \mathrm{mM}$ sucrose and protease inhibitors (Complete, Roche)) and after a quick vortex cells were kept on ice for $30 \mathrm{~min}$. The mixture was then flushed a few times using $26 \mathrm{G}$ needle. Centrifugation at $1,000 \times g$ for $10 \mathrm{~min}$ at $4{ }^{\circ} \mathrm{C}$ allowed us to recover the supernatant containing the cytoplasmic fraction while the nuclear fraction was pelleted. Finally, the nuclear pellet was sonicated for $6 \mathrm{~min}$ (1-min ON and 1-min OFF) at high intensity using the Bioruptor sonicator.

Mass spectrometry analysis. Purified naive $T$ cells were differentiated into $T_{H} 9$ cells for $24 \mathrm{~h}$, and endogenous PU.1 complex was immunopurified as described above. PU.1 complex was then separated on a 4 to $12 \%$ polyacrylamide gel (Invitrogen) and stained with coomassie from Bio-Rad (G-250 Stain) according to the manufacturer's instructions. Mass spectrometry identification of proteins was carried out by R. Tomaino at Taplin Mass Spectometry Facility at Harvard Medical School (Boston, MA, USA).

Proximase ligation assay. Purified naive $\mathrm{T}$ cells were differentiated into $\mathrm{T}_{\mathrm{H}} 9$ cells for $24 \mathrm{~h}$. Cells were fixed with $4 \%$ paraformaldehyde for $15 \mathrm{~min}$ at room temperature and permeabilized with ice-cold $\mathrm{MetOH}$ for $10 \mathrm{~min}$. After being blocked with a solution containing $0.5 \%$ bovine serum albumin in phosphatebuffered saline for $30 \mathrm{~min}$ at room temperature, the cells were incubated with the primary antibody overnight at $4{ }^{\circ} \mathrm{C}$. Then, PLA was performed with Duolink In situ reagents according to the manufacturer's instructions. Images were acquired using Zeiss Axio Imager M2 microscope.

Antibodies. The antibodies were as follows: anti-APG5 (FL-275 Santa Cruz sc-33210, dilution 1:1,000) for WB, anti-LC3B (Sigma-Aldrich L7543, dilution 1:100) for WB and PLA, anti-p-Stat6 pY641 (BD Pharmingen 558241, dilution 1:1000) for WB, anti-Stat6 (Cell Signaling 9362, dilution 1:1000 for WB and 1:500 for PLA) for WB and PLA, anti-IRF4 (M-17 Santa Cruz sc-6059, dilution 1:1000 for WB and 1:500 for PLA) for WB and PLA, anti-GATA-3 (HG3-31 Santa Cruz sc-268, dilution 1:1000 for WB) for WB and anti-GATA-3 (H-48 Santa Cruz, dilution 1:500) for PLA, anti-PU.1 (T-21 Santa Cruz sc-352, $10 \mu \mathrm{g})$ for IP and (D-19 sc-5949, dilution 1:100) for PLA, anti-PU.1 (Cell Signaling 2266, dilution 1:100) for WB, anti-p62 (G962-C Progen, dilution 1:1000) for WB, mono- and polyubiquitinylated conjugates, mAb (FK2) HRP conjugate (Enzo BML-pw0150 dilution 1:1000) for WB, K48-linkage specific-polyubiquitin (D9D5 Cell Signaling 12805, dilution 1:1000) for PLA, K63-linkage specific-polyubiquitin (D7A11 Cell Signaling 12930, dilution 1:500) for PLA, anti- $\beta$-actin (Sigma-Aldrich, dilution 1:1000), Rabbit, Goat and Mouse IgG Isotype Control (Thermo Scientific, dilution 1:500 for PLA and $10 \mu \mathrm{g}$ for IP) for IP and PLA, paxillin antibody B2 (Santa Cruz sc-365379, dilution 1:1000) and HDAC1 (Cell Signaling 2062, dilution $1: 1000)$ for WB.

Drug treatment. Chloroquine diphosphate (Sigma-Aldrich c6628) treatment: purified naive $T$ cells were differentiated for 24 to $72 \mathrm{~h}$ into $\mathrm{T}_{\mathrm{H}} 9$ cells with chloroquine added at a final concentration of $25 \mu \mathrm{M}$ (unless otherwise specified). Metformin hydrochloride (Sigma-Aldrich PHR1084) treatment: purified naive $\mathrm{T}$ cells were differentiated for 24 to $72 \mathrm{~h}$ into $\mathrm{T}_{\mathrm{H}} 9$ cells with metformin added at a final concentration of $1 \mathrm{mM}$ (unless otherwise specified).

DRB (Sigma-Aldrich D1916) treatment: purified naive T cells were differentiated for $16 \mathrm{~h}$ into $\mathrm{T}_{\mathrm{H}} 9$ cells and then $25 \mu \mathrm{g} \mathrm{ml}^{-1}$ of DRB was added for $8 \mathrm{~h}$ Cycloheximide (Sigma-Aldrich C 1988) treatment: purified naive T cells were differentiated into $\mathrm{T}_{\mathrm{H}} 9$ cells with cycloheximide added at a final concentration of $25 \mathrm{\mu g} \mathrm{ml}^{-1}$ during $0,3,6,12$ and $24 \mathrm{~h}$.

MG132 (Sigma-Aldrich Z-Leu-Leu-Leu-al C2211) treatment: purified naive $\mathrm{T}$ cells were differentiated into $\mathrm{T}_{\mathrm{H}} 9$ cells with MG132 added at a final concentration of $2 \mathrm{mM}$ during $24 \mathrm{~h}$.

Real-time quantitative PCR. Total RNA from T cells was extracted with TriReagent (Ambion), reverse transcribed using M-MLV Reverse Transcriptase (Invitrogen) and was analysed by RT-qPCR with the Sybr Green method according to the manufacturer's instructions using the 7500 Fast Real Time PCR system (Applied Biosystems). Expression was normalized to the expression of mouse Actb Primers designed to assess gene expression are as follows: Actb $5^{\prime}$-atggaggggaatacagccc- $3^{\prime}$ and $5^{\prime}$-ttctttgcagctccttcgtt- $3^{\prime}$; Ifng $5^{\prime}$-gagctcattgaatgcttggc- $3^{\prime}$ and $5^{\prime}$-gcgtcattgaatcacacctg- $3^{\prime} ;$ Il4 5' -cgagctcactctctgtggtg- $3^{\prime}$ and $5^{\prime}$-tgaacgaggtcacag gagaa-3'; Il5 5'-catttccacagtacccccac- $3^{\prime}$ and $5^{\prime}$-gcaatgagacgatgaggctt-3'; Il9 $5^{\prime}$-aacagtccctccetgtagca- $3^{\prime}$ and $5^{\prime}$-aaggatgatccaccgtcaaa- $3^{\prime}$; Il10 $5^{\prime}$-tgtcaaattcattcatggcct- $3^{\prime}$ and $5^{\prime}$-atcgatttctcccctgtgaa- $3^{\prime}$; Il13; Il17a $5^{\prime}$-tgagcttcccagatcacaga- $3^{\prime}$ and $5^{\prime}$-tccagaaggcctcagacta- $3^{\prime}$; Il21 $5^{\prime}$-aaaacaggcaaaagctgcat- $3^{\prime}$ and $5^{\prime}$ - 
tgacattgttgaacagctgaaa-3'; Ill $35^{\prime}$-ggtcaaaggtttggaagcag-3' and 5'tgtgaaatgccaccttttga-3'; Stat6 $5^{\prime}$-tgcccggtctcacctaacta- $3^{\prime}$ and $5^{\prime}$-ctggggtggtttcctcttg3'; Irf4 5'-caaagcacagagtcacctgg-3' and 5'-tgcaagctctttgacacaca-3'; Gata3 5'aggatgtccctgctctcctt- $3^{\prime}$ and $5^{\prime}$-gcctgcggactctaccataa-3'; Sfpil $5^{\prime}$-tgcagctctgtgaagtggtt$3^{\prime}$ and $5^{\prime}$-agcgatggagaaagccatag-3'; Foxp $35^{\prime}$-ctcgtctgaaggcagagtca-3' and 5'tggcagagaggtattgaggg- $3^{\prime}$.

Statistical analyses. Statistical analysis was performed using Prism software (Graph Pad software, La Jolla, CA, USA). Student's $t$-test and analysis of variance test were used for statistical analyses.

Data availability. All relevant data are available from the authors.

Received: 18 October 2016 Accepted: 2 July 2017

Published online: 15 September 2017

\section{References}

1. Mizushima, N. \& Komatsu, M. Autophagy: renovation of cells and tissues. Cell 147, 728-741 (2011).

2. Levine, B. \& Kroemer, G. Autophagy in the pathogenesis of disease. Cell 132, 27-42 (2008).

3. Levine, B., Mizushima, N. \& Virgin, H. W. Autophagy in immunity and inflammation. Nature 469, 323-335 (2011).

4. Geng, J. \& Klionsky, D. J. The Atg8 and Atg12 ubiquitin-like conjugation systems in macroautophagy. 'Protein modifications: beyond the usual suspects' review series. EMBO Rep. 9, 859-864 (2008).

5. Fujita, N. et al. The Atg16L complex specifies the site of LC3 lipidation for membrane biogenesis in autophagy. Mol. Biol. Cell. 19, 2092-2100 (2008).

6. Johansen, T. \& Lamark, T. Selective autophagy mediated by autophagic adapter proteins. Autophagy 7, 279-296 (2011).

7. Lin, X. et al. Interaction domains of p62: a bridge between p62 and selective autophagy. DNA Cell Biol. 32, 220-227 (2013).

8. Galluzzi, L. et al. Autophagy in malignant transformation and cancer progression. EMBO J. 34, 856-880 (2015).

9. White, E. The role for autophagy in cancer. J. Clin. Invest. 125, 42-46 (2015).

10. Huijbers, A. et al. The effect of the ATG16L1 Thr300Ala polymorphism on susceptibility and outcome of patients with epithelial cell-derived thyroid carcinoma. Endocr. Relat. Cancer 19, L15-L18 (2012).

11. Grimm, W. A. et al. The Thr300Ala variant in ATG16L1 is associated with improved survival in human colorectal cancer and enhanced production of type I interferon. Gut 65, 456-464 (2016)

12. Pua, H. H., Dzhagalov, I., Chuck, M., Mizushima, N. \& He, Y. W. A critical role for the autophagy gene Atg5 in T cell survival and proliferation. J. Exp. Med. 204, 25-31 (2007).

13. Kovacs, J. R. et al. Autophagy promotes T-cell survival through degradation of proteins of the cell death machinery. Cell Death Differ. 19, 144-152 (2012).

14. Jia, W. \& He, Y. W. Temporal regulation of intracellular organelle homeostasis in T lymphocytes by autophagy. J. Immunol. 186, 5313-5322 (2011).

15. Puleston, D. J. et al. Autophagy is a critical regulator of memory CD8(+) T cell formation. eLife 3, e03706 (2014).

16. Wei, J. et al. Autophagy enforces functional integrity of regulatory T cells by coupling environmental cues and metabolic homeostasis. Nat. Immunol. 17, 277-285 (2016)

17. Li, C. et al. Autophagy is induced in CD4+ T cells and important for the growth factor-withdrawal cell death. J. Immunol. 177, 5163-5168 (2006).

18. Ichimura, Y. et al. A ubiquitin-like system mediates protein lipidation. Nature. 408, 488-492 (2000).

19. Mizushima, N. et al. A protein conjugation system essential for autophagy. Nature 395, 395-398 (1998).

20. Nishida, Y. et al. Discovery of Atg5/Atg7-independent alternative macroautophagy. Nature 461, 654-658 (2009).

21. Klionsky, D. J. et al. Guidelines for the use and interpretation of assays for monitoring autophagy (3rd edition). Autophagy 12, 1-222 (2016).

22. Mizushima, N., Yoshimori, T. \& Levine, B. Methods in mammalian autophagy research. Cell 140, 313-326 (2010).

23. Rubinsztein, D. C., Gestwicki, J. E., Murphy, L. O. \& Klionsky, D. J. Potential therapeutic applications of autophagy. Nat. Rev. Drug. Discov. 6, 304-312 (2007).

24. Paolicchi, E. et al. Targeting hypoxic response for cancer therapy. Oncotarget 7 , 13464-13478 (2016)

25. Hur, K. Y. \& Lee, M. S. New mechanisms of metformin action: focusing on mitochondria and the gut. J. Diabetes Investig. 6, 600-609 (2015).

26. Licona-Limon, P. et al. Th9 cells drive host immunity against gastrointestinal worm infection. Immunity 39, 744-757 (2013).
27. Hara, K. et al. Amino acid sufficiency and mTOR regulate p70 S6 kinase and eIF-4E BP1 through a common effector mechanism. J. Biol. Chem. 273 , 14484-14494 (1998).

28. Dardalhon, V. et al. IL-4 inhibits TGF-beta-induced Foxp3+ T cells and, together with TGF-beta, generates IL-9+IL-10+Foxp3(-) effector T cells. Nat. Immunol. 9, 1347-1355 (2008).

29. Katsuragi, Y., Ichimura, Y. \& Komatsu, M. p62/SQSTM1 functions as a signaling hub and an autophagy adaptor. FEBS J. 282, 4672-4678 (2015).

30. Moscat, J. \& Diaz-Meco, M. T. p62 at the crossroads of autophagy, apoptosis, and cancer. Cell 137, 1001-1004 (2009).

31. Hallier, M., Tavitian, A. \& Moreau-Gachelin, F. The transcription factor Spi-1/ PU.1 binds RNA and interferes with the RNA-binding protein p54nrb. J. Biol. Chem. 271, 11177-11181 (1996).

32. Paul, S. \& Schaefer, B. C. Selective autophagy regulates T cell activation. Autophagy 8, 1690-1692 (2012).

33. Vegran, F. et al. The transcription factor IRF1 dictates the IL-21-dependent anticancer functions of TH9 cells. Nat. Immunol. 15, 758-766 (2014)

34. Purwar, R. et al. Robust tumor immunity to melanoma mediated by interleukin-9-producing T cells. Nat. Med. 18, 1248-1253 (2012).

35. Muranski, P. et al. Tumor-specific Th17-polarized cells eradicate large established melanoma. Blood 112, 362-373 (2008).

36. Lu, Y. et al. Th9 cells promote antitumor immune responses in vivo. J. Clin. Invest. 122, 4160-4171 (2012).

37. Veldhoen, M. et al. Transforming growth factor-beta 'reprograms' the differentiation of $\mathrm{T}$ helper 2 cells and promotes an interleukin 9-producing subset. Nat. Immunol. 9, 1341-1346 (2008).

38. Nakatsukasa, H. et al. The DNA-binding inhibitor Id3 regulates IL-9 production in CD4(+) T cells. Nat. Immunol. 16, 1077-1084 (2015).

39. Kim, I. K. et al. Glucocorticoid-induced tumor necrosis factor receptor-related protein co-stimulation facilitates tumor regression by inducing IL-9-producing helper T cells. Nat. Med. 21, 1010-1017 (2015).

40. Chang, H. C. et al. The transcription factor PU.1 is required for the development of IL-9-producing T cells and allergic inflammation. Nat. Immunol. 11, 527-534 (2010).

41. Nishiyama, C. et al. Functional analysis of PU.1 domains in monocyte-specific gene regulation. FEBS Lett. 561, 63-68 (2004).

42. Konishi, Y. \& Tominaga, A. PU.1 is degraded in differentiation of erythrocytes through a proteasome-dependent pathway. DNA Cell Biol. 25, 340-345 (2006).

43. Kabat, A. M. et al. The autophagy gene Atg1611 differentially regulates Treg and TH2 cells to control intestinal inflammation. eLife 5, e12444 (2016).

44. Michalek, R. D. et al. Cutting edge: distinct glycolytic and lipid oxidative metabolic programs are essential for effector and regulatory $\mathrm{CD} 4+\mathrm{T}$ cell subsets. J. Immunol. 186, 3299-3303 (2011).

45. Wan, Y. Y. GATA3: a master of many trades in immune regulation. Trends Immunol. 35, 233-242 (2014).

46. Abdel Fattah, E., Bhattacharya, A., Herron, A., Safdar, Z. \& Eissa, N. T. Critical role for IL-18 in spontaneous lung inflammation caused by autophagy deficiency. J. Immunol. 194, 5407-5416 (2015).

47. Zhao, J. et al. Celastrol ameliorates experimental colitis in IL-10 deficient mice via the up-regulation of autophagy. Int. Immunopharmacol. 26, 221-228 (2015).

48. Hubbard-Lucey, V. M. et al. Autophagy gene Atg16L1 prevents lethal T cell alloreactivity mediated by dendritic cells. Immunity 41, 579-591 (2014).

49. Ravindran, R. et al. The amino acid sensor GCN2 controls gut inflammation by inhibiting inflammasome activation. Nature 531, 523-527 (2016).

50. Liu, J. Z. et al. Association analyses identify 38 susceptibility loci for inflammatory bowel disease and highlight shared genetic risk across populations. Nat. Genet. 47, 979-986 (2015).

51. Gerlach, K. et al. TH9 cells that express the transcription factor PU.1 drive $\mathrm{T}$ cell-mediated colitis via IL-9 receptor signaling in intestinal epithelial cells. Nat. Immunol. 15, 676-686 (2014).

52. Nalleweg, N. et al. IL-9 and its receptor are predominantly involved in the pathogenesis of UC. Gut 64, 743-755 (2015).

53. Gerlach, K., McKenzie, A. N., Neurath, M. F. \& Weigmann, B. IL-9 regulates intestinal barrier function in experimental T cell-mediated colitis. Tissue Barriers 3, e983777 (2015).

\section{Acknowledgements}

The authors are supported by grants from the Ligue Nationale contre le Cancer (to F.G.) the Fondation de France (to L.A. and T.R.V.), the Institut National du Cancer (to F.G.) the Fondation ARC pour la recherche sur le cancer (to L.A.), the Institut Mérieux (to L. A.), the Conseil Régional de Bourgogne (to F.G. and L.A.), the FEDER, the Agence Nationale de la Recherche (ANR-13-JSV3-0001) (to L.A.) and (ANR-11-LABX-0021), the ARSEP (to L.A. and M.D.), the Ligue Régionale contre le cancer Comite Grand-Est (to L.A.) and the European Commission (Marie Curie Fellowship PCIG10-GA-2011303719) and ERC starting grant (677251) (to L.A.). 


\section{Author contributions}

T.R.V. and Z.C. performed in vitro and in vivo experiments, Y.S. and M.D. performed in vivo experiments, A.R., T.M. and I.B.-L. performed in vitro and in vivo experiments and R.A.F. provided essential material to perform the study. L.A. and T.R.V. wrote the manuscript. F.G. and L.A. supervised the study.

\section{Additional information}

Supplementary Information accompanies this paper at doi:10.1038/s41467-017-00468-w.

Competing interests: The authors declare no competing financial interests.

Reprints and permission information is available online at http://npg.nature.com/ reprintsandpermissions/

Publisher's note: Springer Nature remains neutral with regard to jurisdictional claims in published maps and institutional affiliations. (c) (i) Open Access This article is licensed under a Creative Commons Attribution 4.0 International License, which permits use, sharing, adaptation, distribution and reproduction in any medium or format, as long as you give appropriate credit to the original author(s) and the source, provide a link to the Creative Commons license, and indicate if changes were made. The images or other third party material in this article are included in the article's Creative Commons license, unless indicated otherwise in a credit line to the material. If material is not included in the article's Creative Commons license and your intended use is not permitted by statutory regulation or exceeds the permitted use, you will need to obtain permission directly from the copyright holder. To view a copy of this license, visit http://creativecommons.org/ licenses/by/4.0/.

(C) The Author(s) 2017 
